\title{
A PROGRAM FOR PLOTTING CIRCLES OF CONSTANT OVERPRESSURE AROUND TARGETED POINTS
}

MAI LIIS JOEL AND DOUGLAS D. LOTTRIDGE

U. S. DEPARTMENT OF COMMERCE NATIONAL BUREAU OF STANDARDS 


\section{THE NATIONAL BUREAU OF STANDARDS}

The National Bureau of Standards is a principal focal point in the Federal Government for assuring maximum application of the physical and engineering sciences to the advancement of technology in industry and commerce. Its responsibilities include development and maintenance of the national standards of measurement, and the provisions of means for making measurements consistent with those standards; determination of physical constants and properties of materials; development of methods for testing materials, mechanisms, and structures, and making such tests as may be necessary, particularly for government agencies; cooperation in the establishment of standard practices for incorpora. tion in codes and specifications; advisory service to government agencies on scientific and technical problems; invention and development of devices to serve special needs of the Government; assistance to industry, business, and consumers in the development and acceptance of commercial standards and simplified trade practice recommendations; administration of programs in cooperation with United States business groups and standards organizations for the development of international standards of practice; and maintenance of a clearinghouse for the collection and dissemination of scientific, tech. nical, and engineering information. The scope of the Bureau's activities is suggested in the following listing of its four Institutes and their organizational units.

Institute for Basic Standards. Electricity. Metrology. Heat. Radiation Physics. Mechanics. Applied Mathematics. Atomic Physics. Physical Chemistry. Laboratory Astrophysics. * Radio Standards Laboratory: Radio Standards Physics; Radio Standards Engineering. ** Office of Standard Reference Data.

Institute for Materials Research. Analytical Chemistry. Polymers. Metallurgy. Inorganic Materials. Reactor Radiations. Cryogenics.** Office of Standard Reference Materials.

Central Radio Propagation Laboratory.* Ionosphere Research and Propagation. Troposphere and Space Telecommunications. Radio Systems. Upper Atmosphere and Space Physics.

Institute for Applied Technology. Textiles and Apparel Technology Center. Building Research. Industrial Equipment. Information Technology. Performance Test Development. Instrumentation. Transport Systems. Office of Technical Services. Office of Weights and Measures. Office of Engineering Standards. Office of Industrial Services.

* NBS Group, Joint Institute for Laboratory Astrophysics at the University of Colorado.

** Located at Boulder, Colorado. 


\section{NATIONAL BUREAU OF STANDARDS Technical Note 249}

ISSUED OCTOBER 28, 1964

\section{A PROGRAM FOR PLOTTING CIRCLES OF CONSTANT OVERPRESSURE AROUND TARGETED POINTS}

Mai Liis Joel and Douglas D. Lottridge

NBS Technical Notes are designed to supplement the Bureau's regular publications program. They provide a means for making available scientific data that are of transient or limited interest. Technical Notes may be listed or referred to in the open literature. 
Contents

Page

List of Illustrations . . . . . . . . . . . . . . . iv

1. Introduction . . . . . . . . . . . . . . 1

2. The Maps . . . . . . . . . . . . . 3

3. The Program . . . . . . . . . . . . . 3

3.1 General . . . . . . . . . . . . . . 3

3.2 Inputs . . . . . . . . . . . . . . . . . 3

3.3 Routines . . . . . . . . . . . . 5

3.4 Outputs . . . . . . . . . . . . 20

3. 5 Operation............ . . . . 24

4. Future Plans . . . . . . . . . . . . . . . 26

5. Acknowledgements . . . . . . . . . . . . 26

6. References . . . . . . . . . . . . 27

Appendix A: Card Formats

Appendix B: Program Listings 


\section{List of Illustrations}

Page

Figure 1. Lethal Radius Plot Program Flow Chart 4

Figure 2. Phase I - Part 1 Flow Chart

Figure 3. Phase I - Part 3 Flow Chart

Figure 4. Standard Parallels of Lambert Conformal Conic Projection

Figure 5. Detail of Lambert Conformal Conic Projection

Figure 6. Phase II Main Program Flow Chart

Figure 7. CIRCLE Subroutine Flow Chart

Figure 8. CalComp Plotter Moves

Figure 9. Basic PLOT Subroutine Flow Chart

Figure 10. SYMBOL Subroutine Flow Chart

Figure 11. Semi-Buffered IBM 709-7090 Tape Write Routine ( $T R W 2$ )

Figure i2. Plot Tape Format 
A Program for Plotting Circles of Constant Overpressure Around Targeted Points

by

Mai Liis Joel

and

Douglas D. Lottridge

\begin{abstract}
The Defense Communications Agency is responsible for locating its communications facilities in a manner that will maximize the probability of maintaining communication in the face of nuclear attack. This report describes a program written for the IBM 7094 which produces as its final output one or more tapes to be used as input to a CalComp 570 plotter system. With these tapes the plotter can produce overlays for use with the series of World Aeronautical Charts covering the Continental United States. The overlays comprise circles representing a radius of constant overpressure around the target point of a given nuclear weapon. Based on hypothetical attacks the overlays provide the user with a means of visualizing the hardness required of facilities to survive in particular areas.
\end{abstract}

\title{
1. Introduction
}

The Defense Communications Agency (DCA) is responsible for the design and implementation of a world-wide communications network. Inherent in such responsibility is the need for DCA to determine where facilities should be located. There are some obvious restrictions in the placement of facilities. Certainly it would be impossible to put facilities in areas controlled by unsympathetic alien powers. Additionally, it is impossible to place facilities in areas which are topographically restrictive. But aside from these more clearly dis cernible restrictions, certain other limitations are imposed.

A major consideration in the design of a modern military network is the maximization of the probability of network survival in the event of a nuclear attack. The National Bureau of Standards (NBS) was asked to develop a method for presenting graphically the danger areas within the Continental United States (CONUS) where communications facilities might be destroyed if a nuclear attack were to take place. 
There are many known effects from a nuclear blast; NBS was asked to consider, at the present time, only the direct blast effect. Data for the project are based on hypothetical attacks which are designed within the Defense Department.

The destructive power of a bomb at a point can be measured in terms of peak overpressure in pounds per square inch (PSI). This overpressure can be calculated from two bomb parameters, height of burst and yield. The distance from the bomb at which the overpressure is calculated is often referred to as the "lethal radius" for that particular PSI value.

The strength of a facility of the communications network to withstand the blast of a bomb is measured in terms of "hardness." If a facility is hardened to 2 PS I, this means that, in all likelihood, it can withstand the blast of bombs with overpressures which are less than 2 PSI at that point. However, if a bomb were to produce an overpressure of 3 PSI at that point, it is likely that the facility would be destroyed.

A factor known as "circular error probable" (CEP) is introduced because it is likely that a bomb targeted at a specific point will not land exactly on that point, but rather will land somewhere in the vicinity of the target. It is possible, therefore, that a facility located immediately outside the lethal radius might be destroyed if the bomb actually hit off target in the direction of the facility. An allowance for this possibility is introduced by adding a specified number of CEP's to the lethal radius. It should be noted, however, that adding CEP's will increase the probability that something located within the radius could actually withstand a blast. The probabilities of these occurrences for given numbers of CEP's have been calculated.

NBS has written a computer program which produces as its final output a magnetic tape which is used as input to the CalComp 570 Magnetic Tape Plotting System. With this tape as input, the CalComp plotter will produce overlays for the series of World Aeronautical Charts (WAC charts). Each of these overlays contains circles which represent lethal radii (including a specified number of $C E P^{\prime} s$ ) around targeted points. Each circle bears a label of the PSI value which it represents. By placing an overlay on the appropriate map, then, it is possible to see to what PSI value a facility would have to be hardened in order to withstand the particular nuclear attack being considered.

It should be emphasized that this program does not consider all factors which are essential to the optimal placement of facilities. It does, however, provide readily available guidelines for determining the required hardness of a facility in a particular locale. It eliminates the need for laborious hand calculations and manual mapping. 


\section{The Maps}

Before the programming effort began, it was necessary to select an appropriate map series. It was decided that a scale of 1 inch $=10$ to 20 miles provided enough detail without requiring too many maps to provide practical coverage of CONUS. The World Aeronautical Chart (WAC) Series was selected because of appropriate scale (1 inch $=16$ miles) and availability. Because the charts are in the Lambert Conformal Conic Projection, the algorithm to convert geographic coordinates to $\mathrm{x}, \mathrm{y}$ coordinates is somewhat more complex than would be required for conversion from a rectangular projection. The algorithm is discussed in more detail in the section entitled Routines.

\section{The Program}

\section{1 General}

This program is written in two phases, both coded for the IBM $7090 / 94$ computers.

Phase $I$ is divided into three parts: the first generates the lethal radius and tags each bomb with the appropriate WAC identification; the second sorts the bombs into ascending WAC chart order; and the third generates the $x$, $y$ coordinates of targeted points and produces the input tape for the second major phase.

Phase II of the main program calculates the codes required to produce circles whose radii correspond to specified overpressures. These codes, as well as control and labeling codes, make up the plotting tapes which are the main outputs of Phase II.

A general flow chart of the entire program is presented in Figure 1.

\subsection{Inputs}

This section briefly discusses the data and control card input requirements for the program. Specific details concerning the formats of all of these cards are presented in Appendix A.

The attack data cards are accepted by Part $i$ of Phase I in a format which was chosen to make the input compatible with that of the National Military Command System (NMCS) Rapid Damage Assessment (RDA) model. Bombs targeted at the same point should be grouped together in the data deck so that the program can take advantage of the duplicate point deletion feature which is discussed in the section on Routines.

Two or more cards containing control and parameter items are placed in front of the data deck. These give the program flexibility in tape assignment, type of output, number of $C E P^{\prime} s$ to be added to the lethal radii, number of radii to be calculated for each bomb, PSI 


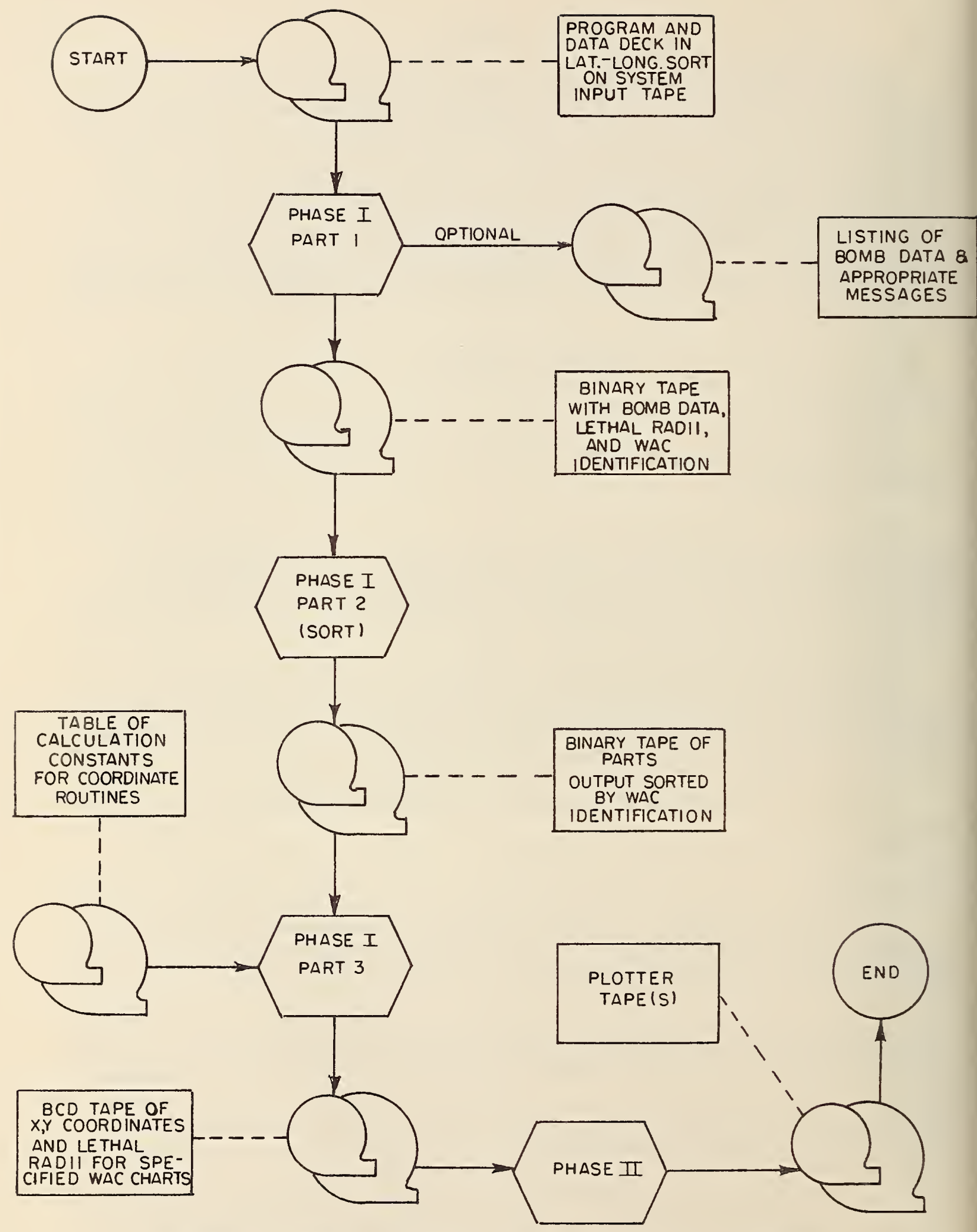

FIGURE 1. LETHAL RADIUS PLOT PROGRAM FLOW CHART 
values to be considered in calculating the radii, number of altitude categories to be considered, and coefficients associated with each altitude calculation. A single control card behind the data deck flags the end of the deck.

The input to Part 2 of Phase $I$ is the binary output tape from Part 1. The required control cards for Part 2 (the IBM IBSYS Sort routine) are coded specifically for this sort and are included in the program package.

There are two input tapes required for Part 3 of the first major phase. One is the sorted tape from Part 2; the other is a binary tape (NBS number 1151) of computational constants for each WAC chart. (These constants are discussed in the following section.)

A single parameter card is placed at the end of the Part 3 program deck. Besides specifying the number of radii to be plotted around each point, it allows the programmer to assign specific tape units to the symbolically named tapes in the program.

Inputs to Phase II consist of the tape produced in Part 3 of Phase I (see section entitled Outputs for format description) and of one control card which specifies the number of hardness categories with their associated PSI values. The date of the run and an option for specifying security classification are also included on the control card.

\subsection{Routines}

Part 1 of Phase $I$ is composed of a main program and two subroutines, all written in FORTRAN. A general flow chart is shown in Figure 2 and a program listing appears in Appendix B. The main program performs general control functions, writes out any necessary diagnostics, deletes duplicate bombs, and calls the following subroutines:

CHART - - This subroutine performs the function of supplying the appropriate WAC identification number for each bomb. The identification number is twice the true WAC chart number for the lower half of a chart, or one plus twice the true WAC chart number for the upper half of a chart.

RLETH - - This subroutine contains the mathematics for computing the lethal radii. The algorithm used is one developed by the RAND Corporation. The basic formula for calculating the lethal radii was taken from Reference 2. The coefficients used for 5,000-foot and ground burst conditions were taken from a listing of the program discussed in Reference 2. As soon as the lethal radius has been computed, the main program adds the specified number of CEP's to it. This gives the radius which is used in plotting. 


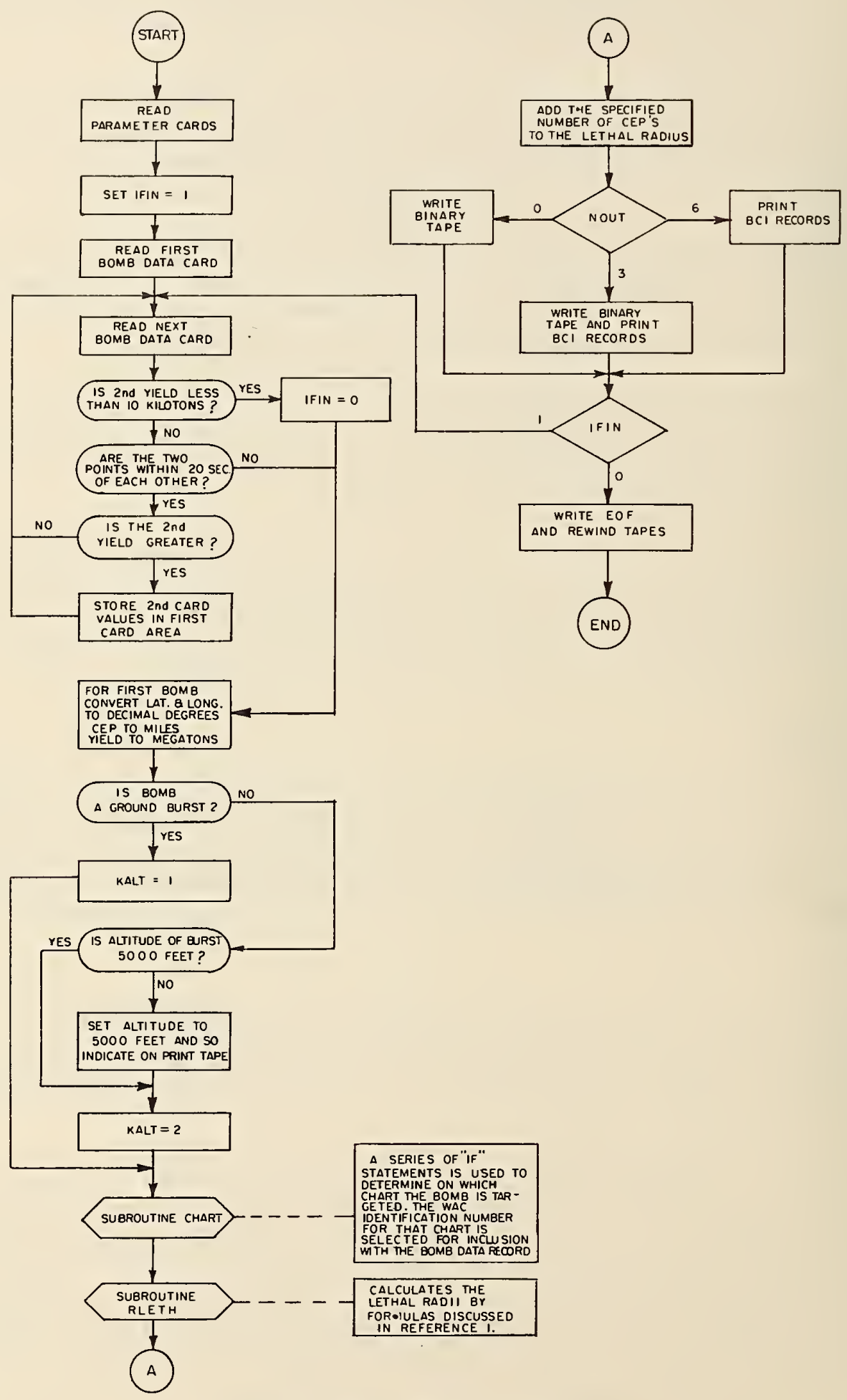

FIGURE 2. PHASE I - PART I FLOW CHART 
The duplicate point deletion feature in Part 1 eliminates redundant plotting of radii around a multiple weapon target area. As cards are read, the target coordinates are matched. If the geographic coordinates are within 20 seconds of arc of each other the larger yield is maintained with the coordinates of the first target. This process continues until a bomb is found which is not targeted within 20 seconds of arc of the first one. At this point the coordinates of the first bomb and the data of the one with the largest yield are made part of the data for plotting. Then the process continues. Since the plotter is insensitive to distances of less than about 6 seconds on the WAC charts, this feature produces virtually no information loss and provides more readable charts.

Part 2 of Phase I is a sort routine run under the IBM IBSYS Monitor System. Its purpose is to arrange the binary records on the Part 1 output tape into ascending order by WAC identification number. The routine was written by IBM and is found on the IBSYS Monitor tape. The control cards required to call the routine are included as part of the program package. Detailed information may be found in Reference 3.

Part 3 of Phase I is a FORTRAN routine which prepares the final Phase I output tape. This tape is used as input to the plotting routines of Phase II. A flow chart of Part 3 appears in Figure 3, and the program listing is given in Appendix B. This routine requires some detailed mathematical procedures to convert geographic positions to $\mathrm{x}$, y coordinates for the WAC overlays. In order to describe the computational procedure a description of the Lambert Conformal Conic Projection must be given.

This projection is of the type which preserves angular relationships in mapped areas. The latitudes (parallels), therefore, are portions of concentric circles and the longitudinal lines (meridians) will intersect at either the north or south pole depending upon whether the mapped area is in the northern or southern hemisphere. (If the central latitude of the projection is the equator the meridians will be parallel.) A given chart will normally be based on two standard parallels. The mathematical relationships among points on the chart are calculated by considering the two standard parallels as the points of intersection of a cone with a sphere. Figure 4 will help clarify this point.

The absence of immediately available values for the angular scale constant and for the meridian radii to given parallels presents a problem in expanding the use of this program to areas outside CONUS. It should readily be seen that any change in standard parallels will change the shape and size of the intersecting cone so that the lengths $\mathrm{R}$ and $\mathrm{r}$ (see Figure 5 ) and the angular scale factor will vary. While this problem may not be insurmountable, considerable effort would be required to derive formulas for computing the necessary constants. 


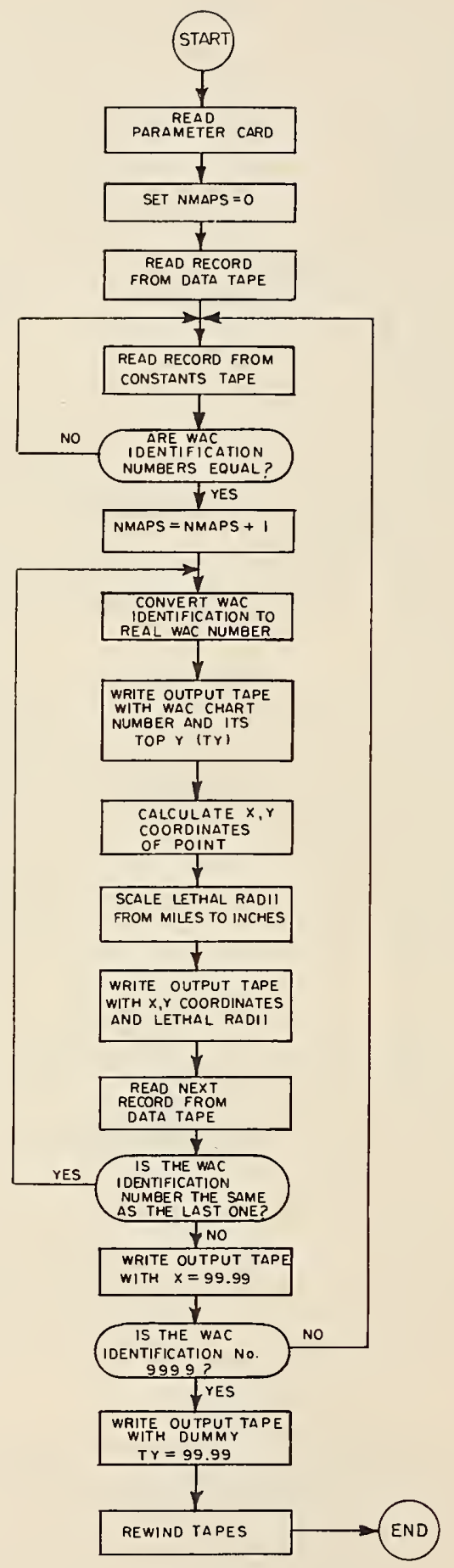

FIGURE 3. PHASE I- PART 3 FLOW CHART 


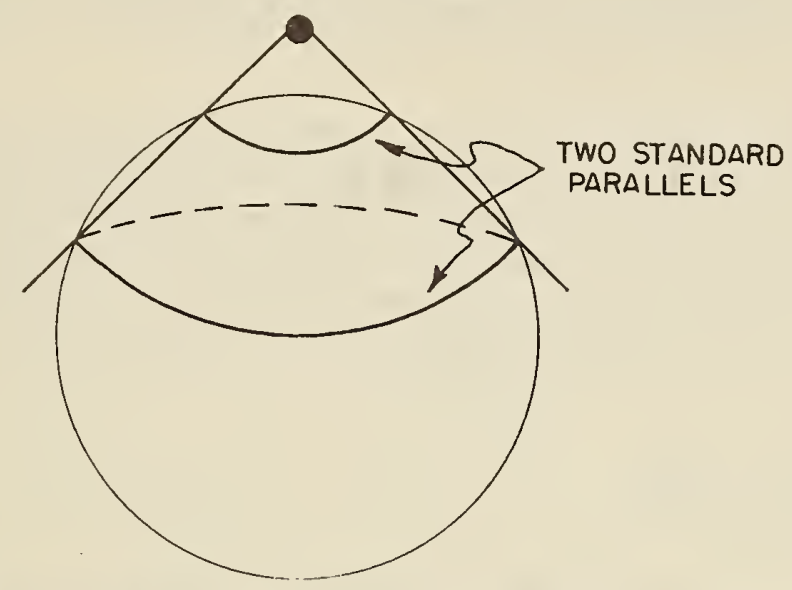

FIGURE 4. STANDARD PARALLELS OF LAMBERT CONFORMAL CONIC PROJECTION

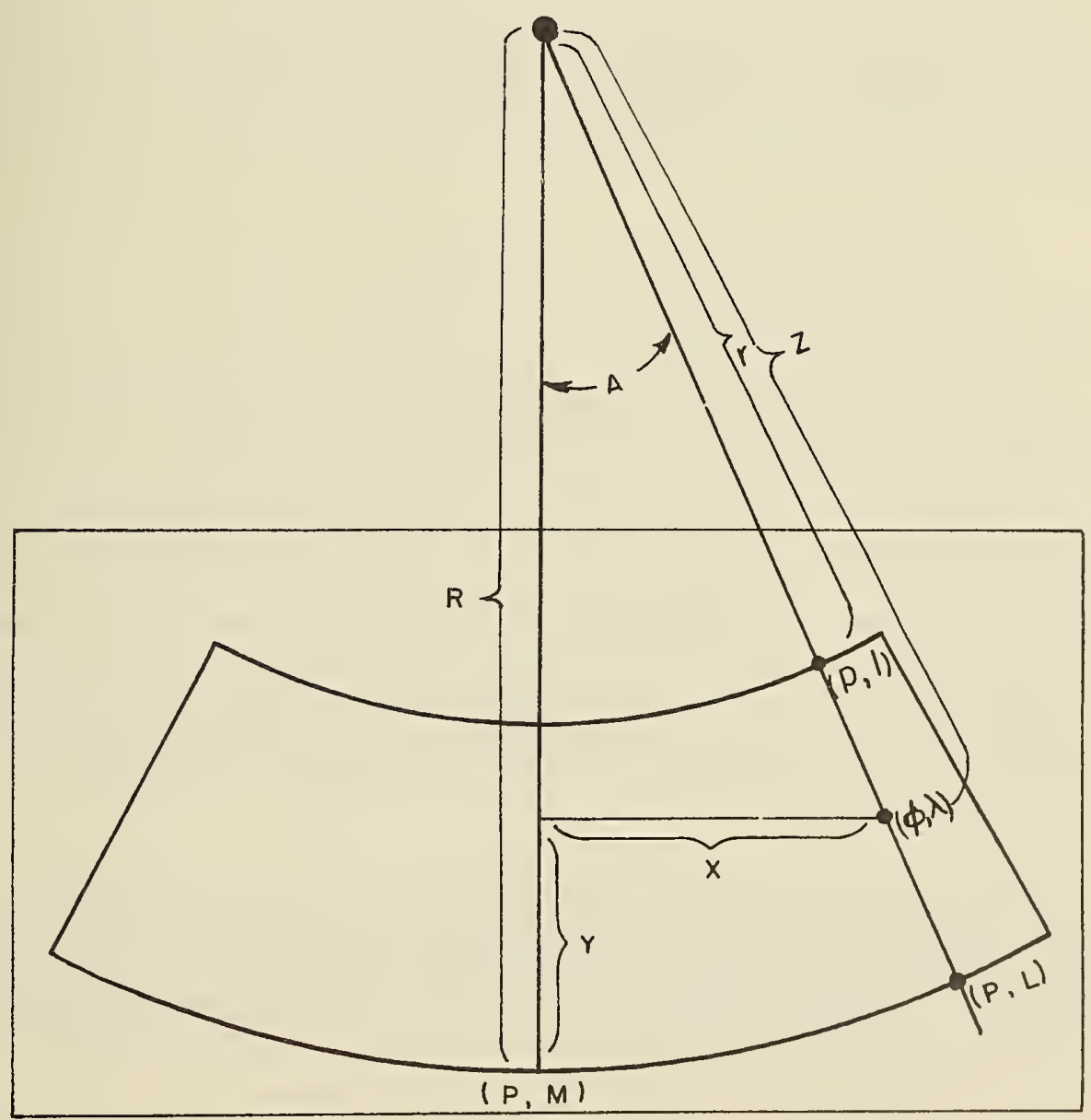

FIGURE 5. DETAIL OF LAMBERT CONFORMAL CONIC PROJECTION 
The formulas for calculating $x$, y coordinates were developed by NBS from information contained in Reference 1. Figure 5 will help to show how the equations were derived.

To calculate the $x, y$ coordinates of the given geographic point $\emptyset$, $\lambda$, the origin $(0,0)$ is set at that point with geographic coordinates $P$, M. Each chart has an upper and lower parallel with latitudes $p$ and $P$ respectively and a central meridian with longitude $M$. Values for $r$, $\mathrm{R}$, and $\mathrm{k}$ (defined below) are available from Reference $\mathrm{l}$ for the WAC chart series of the United States with standard parallels of $33^{\circ}$ and $45^{\circ}$. The calculations are as follows:

$$
\begin{aligned}
& \frac{R-Z}{R-r}=\frac{P-\emptyset}{P-P} \\
& Z=R-\frac{(P-\emptyset)(R-r)}{P-P}
\end{aligned}
$$

Let

$$
\theta=M-\lambda
$$

and $\mathrm{k}=\mathrm{a}$ scale constant for angular correction (required when representing a spherical surface on a plane surface).

Then $\quad A=k \theta$

$$
\begin{aligned}
& x=Z \sin A \\
& y=R-Z \cos A
\end{aligned}
$$

It is now appropriate to specify the contents of the tape of constants (NBS 1151) which is used as input to Part 3. For each chart the tape contains the WAC identification number, the central meridian $(M)$ of the chart in decimal degrees, the maximum value (TY) in inches on $M$, the unscaled meridian radius $(R)$ in meters to the lower parallel, the unscaled difference $(R-r)$ in meters between the meridian radii to the upper and lower parallels, and the latitude $(P)$ of the lower parallel. The meridian radii to parallels are given for 30-minute intervals in Reference l. The symbolic names used for these quantities in the program may differ from those used in this description because of FORTRAN requirements and the desire for simplicity in this presentation.

Eight subroutines and a main program which calls these subroutines make up the Phase II program package. The main program and the CIRCLE and CONVRT subroutines were written at NBS specifically for this project. The remaining subroutines are more general, being part of the Standard CalComp On-line Off-line Plotting 
(SCOOP) package. See Reference 4. 1/ However, two of these subroutines (PLOT and MCG) have been modified for use in this program and, therefore, should no longer be considered general purpose plotting routines.

The remainder of this section contains descriptions and flow charts (when necessary) of the routines used in Phase II. Figures 9 , 10 , and i i have been taken directly from the SCOOP manual. Because of its importance in this problem, the CIRCLE subroutine is described in much greater detail than the others. Appendix B contains listings of all routines in the form required by this program.

Phase II Main Program - - The main program, which is written in FORTRAN, reads the input tape and control card, calls the various subroutines necessary for producing a plotter tape, and produces a listing which shows the correspondence between WAC coverage and location (picture number) on the output tape. See Figure 6.

CIRCLE (CY, R, M, NUMB) -- This FORTRAN subroutine calculates the moves required to produce circles with specific radii. CY represents the y coordinate of the center of the circle and is expressed in floating point inches from the origin. $R$ is the radius in inches, also expressed in floating point. The last two arguments (M, NUMB) are outputs used to call the internal subroutine CONVRT. The transfer vector is convert; that is, the subroutine transfers to CONVRT. See Figure 7.

In order to understand how CIRCLE works, it is necessary to know the following two facts about the CalComp plotter: (1) the plotter can move in eight directions; and (2) each move has a 0.01-inch projection horizontally or vertically, or both. CIRCLE produces a certain number (NUMB) of integers (M) from 0 to 8 . These integers correspond to a "no move" code (0) and to the eight possible plotter moves. See Figure 8.

If a circle is divided into eight sectors, a certain combination of only two plotter moves is required to draw the arc for any given sector. For example, the arc from $0^{\circ}$ to $45^{\circ}$ may be drawn using only north (1) and northwest (8) moves. Similarly, the $45^{\circ}$ to $90^{\circ}$ arc would require only northwest (8) and west (7) moves, and so on. As long as whole circles are drawn this remains true.

Permission to reproduce material from Reference 4 was given by California Computer Products, Inc. This material may not be reproduced except when authorized by that company. 

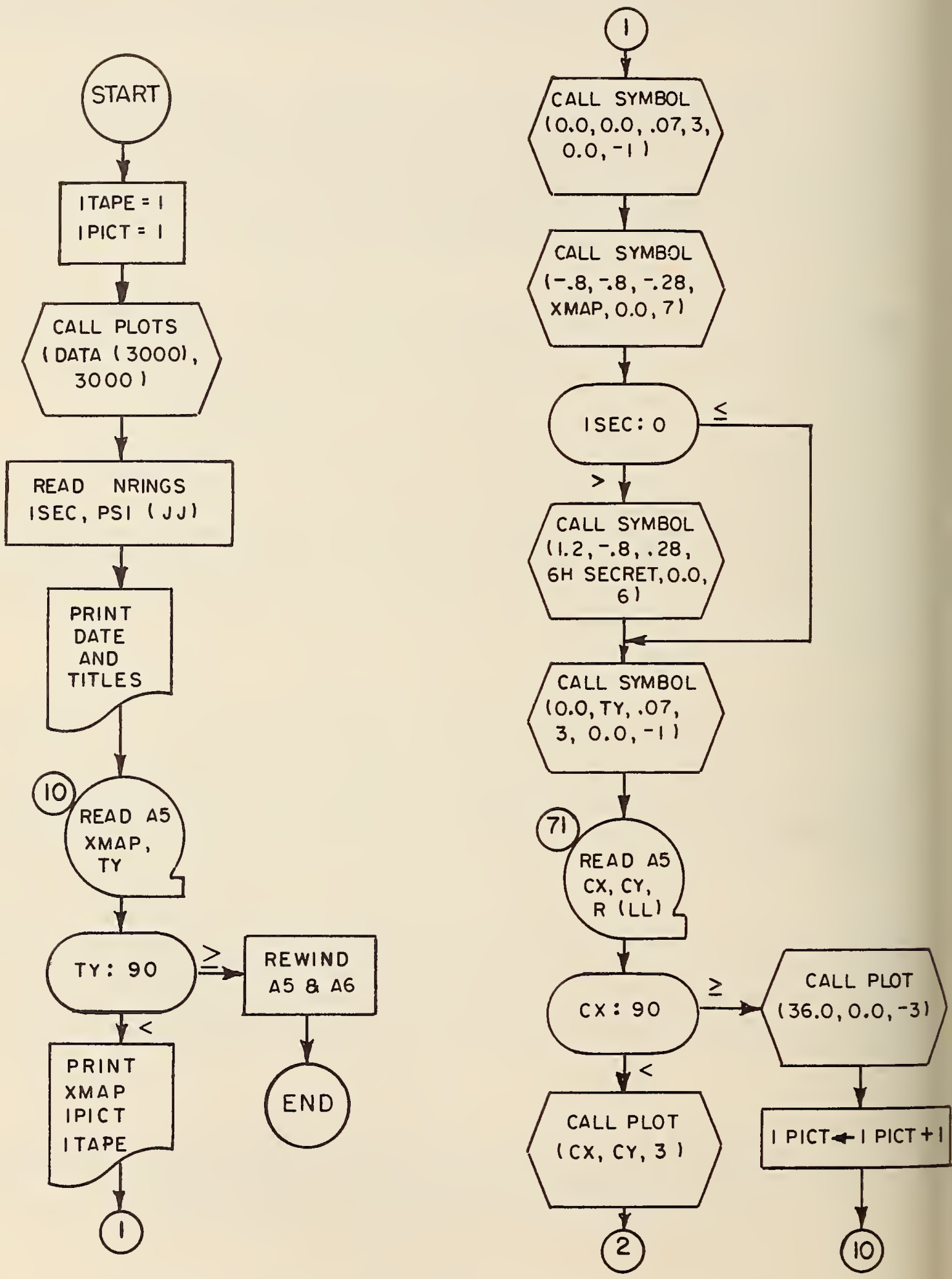

FIGURE 6. PHASE II MAIN PROGRAM FLOW CHART 


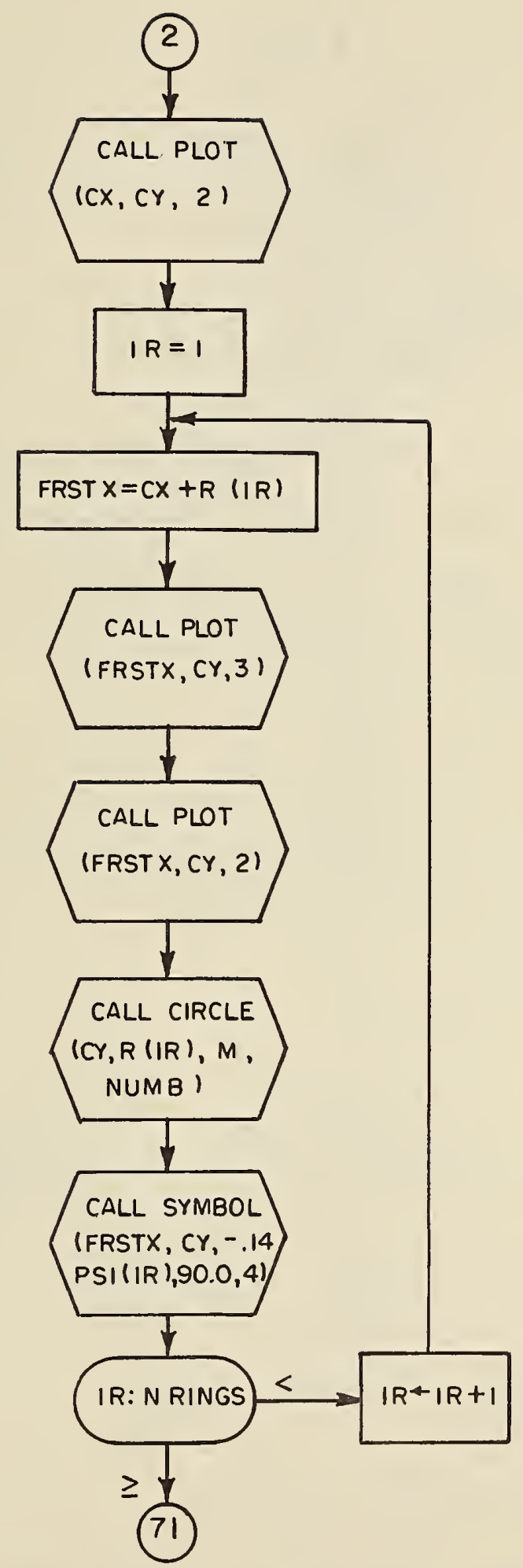

FIGURE 6. (continued) 


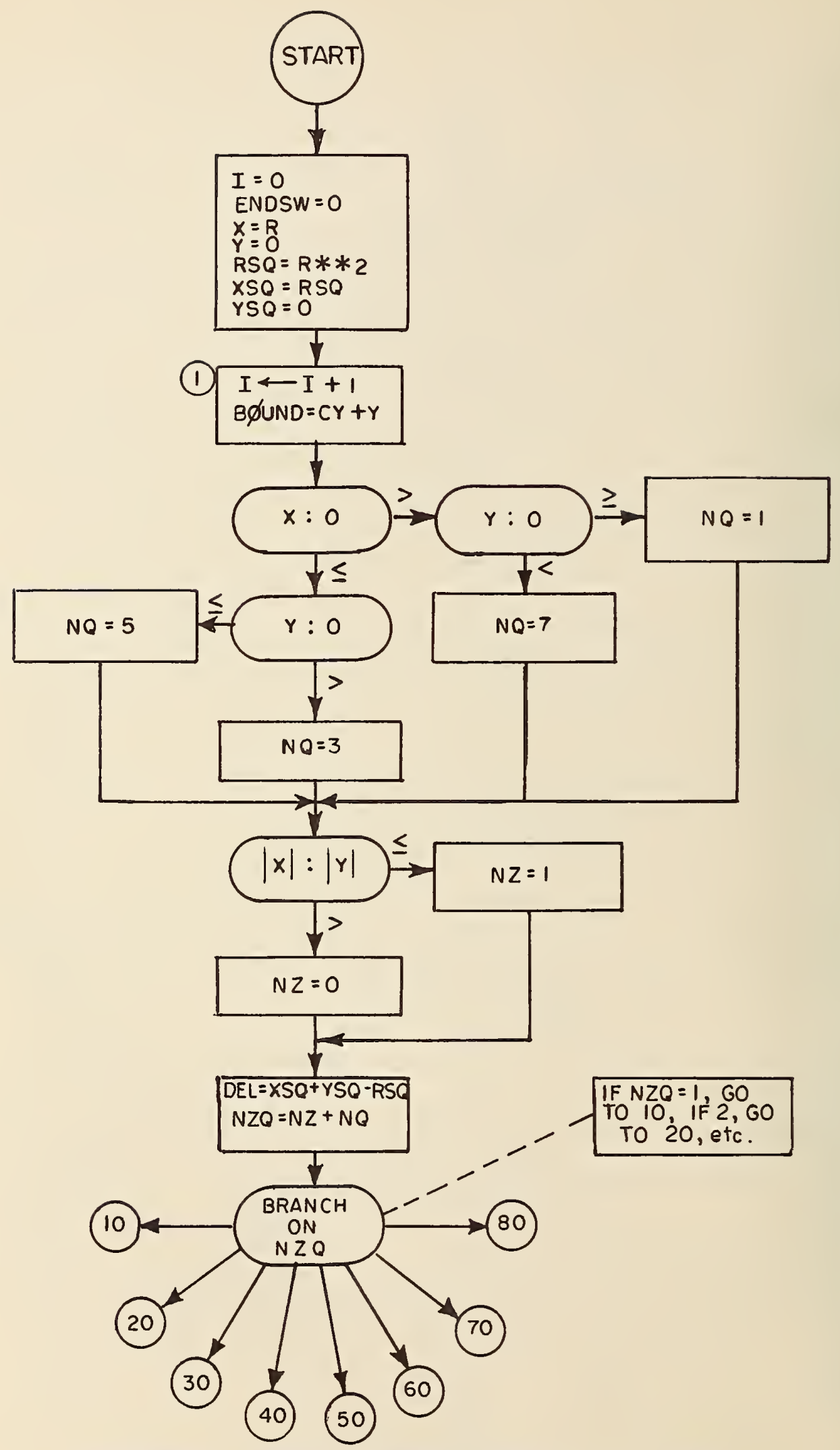

FIGURE 7. CIRCLE SUBROUTINE FLOW CHART CALL CIRCLE (CY, R, M, NUMB) 


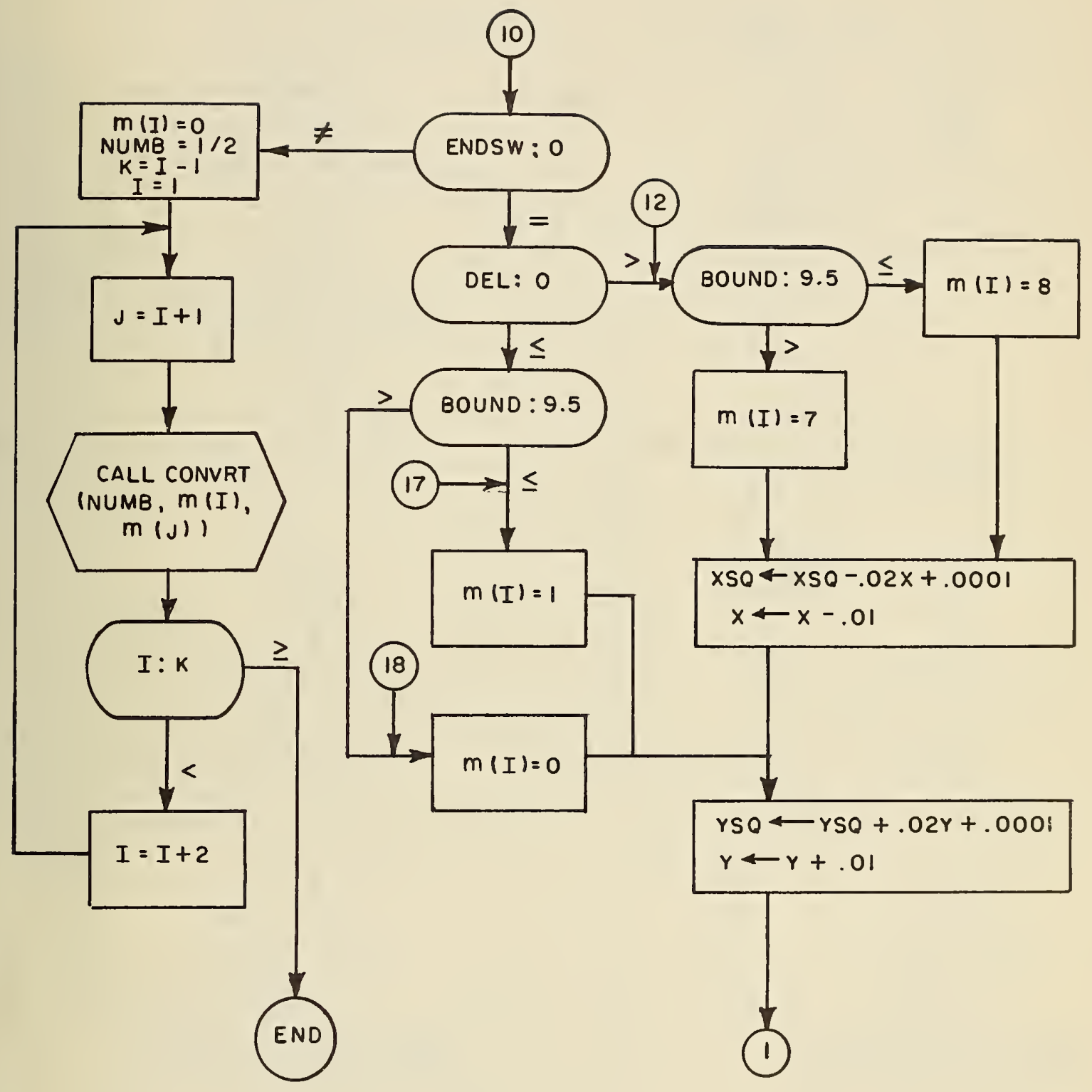

FIGURE 7. ( continued) 


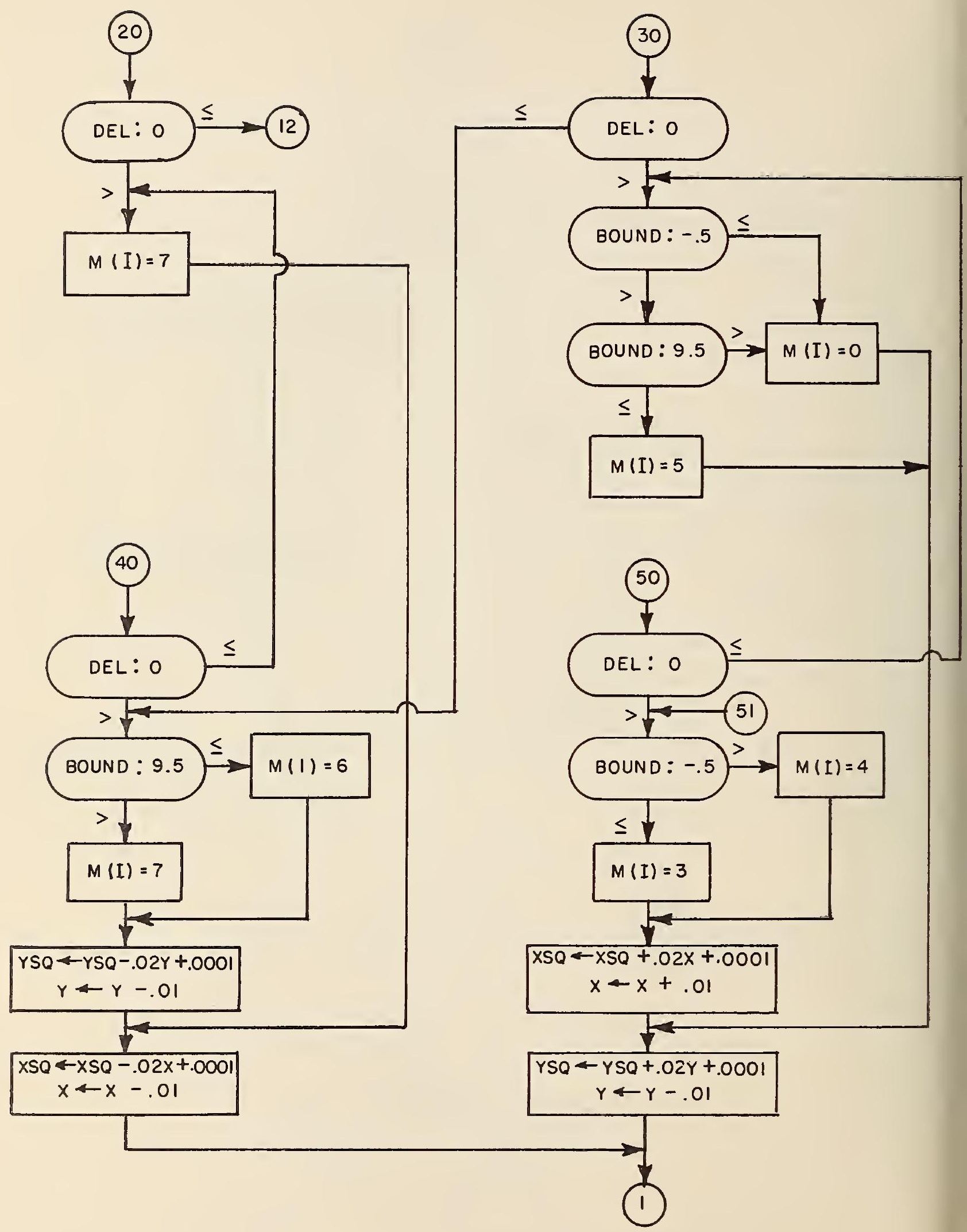

FIGURE 7. (continued) 


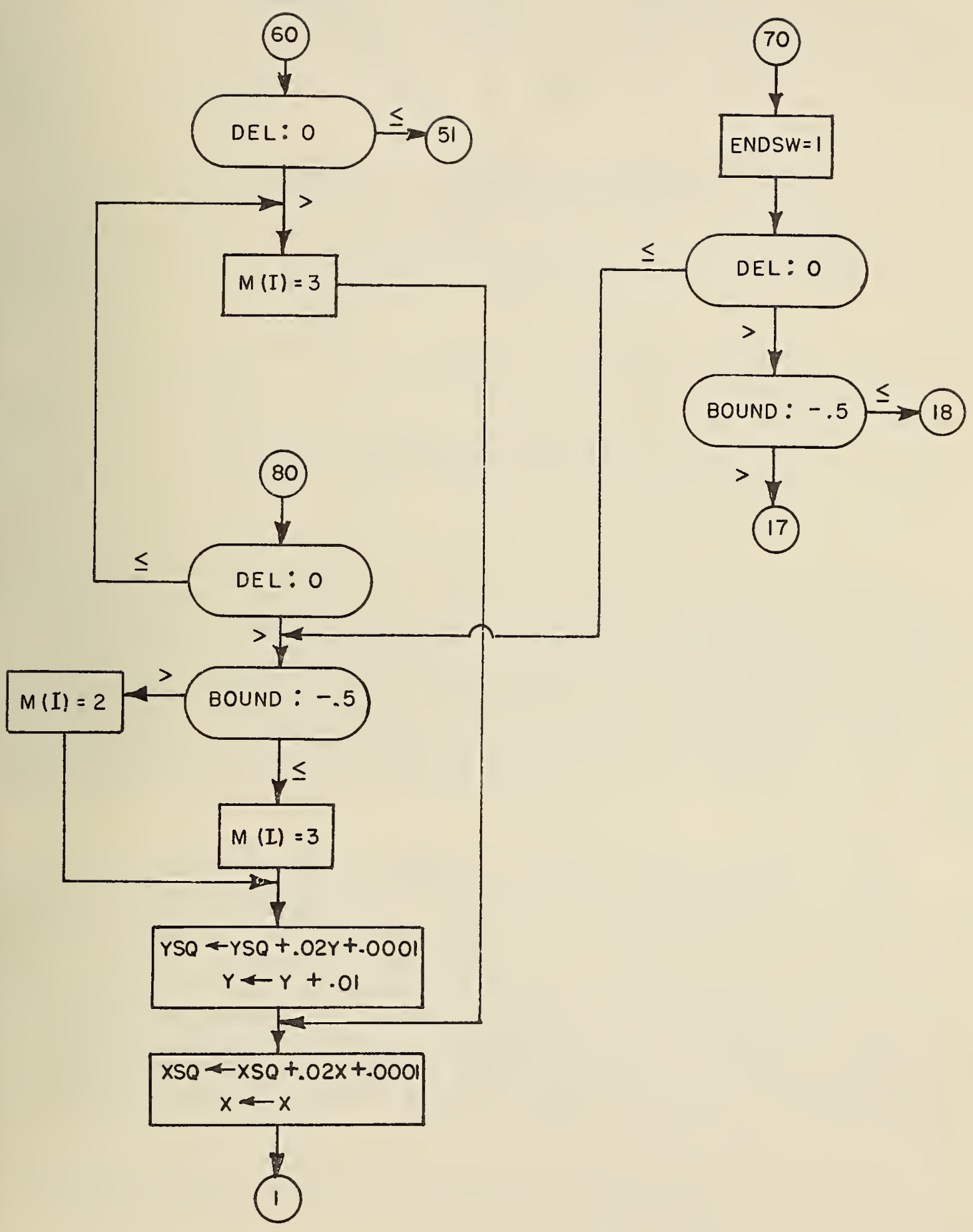

FIGURE 7. (continued) 


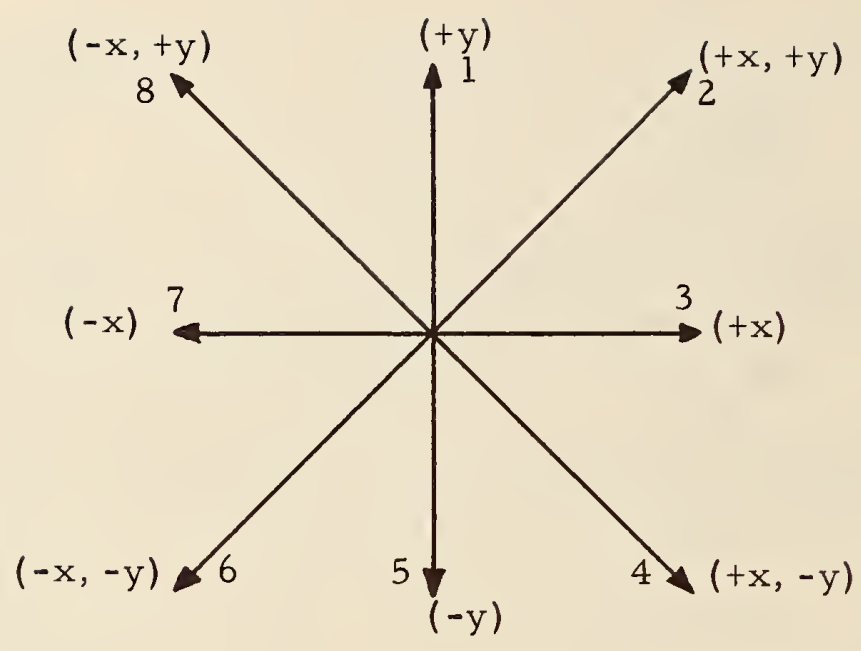

Figure 8. CalComp Plotter Moves

However, if truncation is necessary to prevent hitting the physical stops at the top or bottom of the plotter, the number of possible plotter moves in any given sector may become as high as four. In these instances substitutions for one or both of the two original moves are made. For example, if in moving from 00 to $45^{\circ}$ either a north (1) or a northwest (8) move would exceed the physical limits of the plotter, a "no-move" code (0) and a west code (7) would need to be substituted for the two original moves. This action would produce a straight line at the top or bottom of a circle and would indicate that the circle had been truncated.

Phase II has been programmed so that when CIRCLE is called the codes have already been produced for positioning the plotter pen at $0^{\circ}$ on the circumference of the circle to be drawn. Since this is true, it is possible for programming purposes to consider the center of the circle as being at a point $\mathrm{x}=0, \mathrm{y}=0$. The initial point on the circumference then becomes $x=r, y=0$. With these new reference points it is relatively simple to determine which sector is being drawn and, therefore, which moves are possible. To determine the sector, one needs only to compare the $\mathrm{x}$ and $\mathrm{y}$ values with zero and the absolute values of $\mathrm{x}$ and $\mathrm{y}$ with each other.

To determine which combination of the two possible moves for a given sector will produce the most perfect circle, the formula for a circle with center at $(0,0)$ is used:

$$
x^{2}+y^{2}=r^{2}
$$


To determine whether, for example, a north or northwest move is preferable, the value $\mathrm{x}^{2}+\mathrm{y}^{2}-\mathrm{r}^{2}(\mathrm{del})$ is computed. If del is equal to zero, the pen is positioned exactly on the circumference of the circle. If it is less than zero, the pen is inside the circle, and if it is greater, it is outside. The value of del, then, indicates the best next move in order to stay closest to the perfect circumference. Each time a move is made the $\mathrm{x}$ and/or $\mathrm{y}$ value is changed by 0.01 inch for the next calculations.

For obvious reasons, tests to determine whether truncation is necessary cannot be made using the hypothetical center $\mathrm{x}=0, \mathrm{y}=0$. Instead, the true center y (CY) value of the circle relative to the overlay is used for truncation tests. The true center $x$ value is never needed, since truncation will occur only at the top and/or bottom of an overlay.

When a circle is truncated, the deleted portion of the circle is not plotted on the adjacent overlay. Although it is relatively simple to visualize the continuation of a truncated circle, it is currently impossible without examining surrounding overlays to know whether or not the area under consideration is affected by bombs targeted near the boundaries of adjacent charts. Further programming would be required to enter parts of circles with centers on adjacent charts. (This is under consideration in future plans.)

CONVRT (NUMB, M(I), M(J)) -- This internal machine language (FAP) subroutine converts a certain number of integers (M) produced in CIRCLE into actual plotter moves. NUMB is the number of computer words (two moves to one word) needed to store these moves. The subroutine then transfers to PLOT with certain control codes as arguments; these codes permit the incorporation of circle-producing plotter moves into the main buffer area.

MSG -- This short, internal, FORTRAN subroutine is used for on-line messages to the computer operator. The original SCOOP version has been modified slightly to aid in producing the listing describedi under MAIN.

PLOT ( $X, Y, I P E N)$-- The primary purpose of this FAP subroutine is to move the pen from its current location to a new one. The secondary purpose is to signal the end of the plot. $X$ and $Y$ are the coordinates of the point to which the pen is to be moved. The up or down condition of the pen during movement is specified by the magnitude of IPEN, where $1=$ no change, $2=$ pen down, and $3=$ pen up. If the sign of IPEN is positive the entrance is a normal plot entrance; if it is negative the entrance is an end-of-plot entrance and the following occurs:

1. The output buffer is written on tape, and 
2. A new reference point is established by storing zero in the present pen position.

The subroutine has been modified to permit the insertion of circle producing codes into the main buffer area. The transfer vector is TRW. See Figure 9.

PLOTS (BUFFER (N), N) -- This short FAP subroutine sets up the tape write routine. BUFFER(N) is the first of $N$ consecutive locations to be used as an output buffer. The transfer vector is TRWS.

SYMBOL (X, Y, HEIGHT, BCD, THETA, N) -- This FAP subroutine draws alphanumeric characters and special symbols on the plot. The coordinates of the lower left-hand corner of the characters are specified for alphanumeric characters; the coordinates of the center of the symbol are specified for special symbols. $X$ and $Y$ are the coordinates of the first character. HEIGHT represents the character height. $\mathrm{BCD}$ is the location of the characters to be printed out or the actual string of characters in the form nHxxxxxx. THETA is the angle with the horizontal at which the characters are to be drawn. The absolute value of $\mathrm{N}$ is the number of characters to be drawn. If $\mathrm{N}$ is positive, the pen will be lifted between characters. When plotting symbols, N should be negative. Transfer vectors are PLOT and the system subroutines SIN and COS. See Figure 10.

TRW (BUFFER) -- This FAP subroutine writes the CalComp plotter commands on tape from an area called BUFFER. If more than one output tape is required, a transfer to MSG takes place.

TRWS (L(B)) - - This FAP subroutine initializes the write buffer. $\mathrm{L}(\mathrm{B})$ is an address containing the following:

PZE BLOCK, , $m$

BLOCK is the first of $m$ consecutive addresses containing the $m$ words to be written on tape. See Figure 11 for both TRW and TRWS.

\subsection{Outputs}

The output from Part 1 of Phase I is normally only a binary tape containing one record for each bomb. Each record contains a WAC identification number, latitude and longitude of the targeted point, and the computed lethal radii to be plotted around that point. The last record contains a false identification number of 9999 to indicate the end of the data. One field of the first parameter card allows the user to call for a BCI printout from Part I. This printout contains detailed information on all bombs to be plotted. Such information includes latitude and longitude of bomb target,altitude category for height of burst, yield, CEP, CEP multiplier for this run, and the lethal radius for each PSI value specified. If any heights of burst have been altered for computational purposes it will be so stated 


\section{SYMBOL SUBROUTINE FLOW CHART CALL SYMBL4 (X,Y,H,BCD, THETA,N}

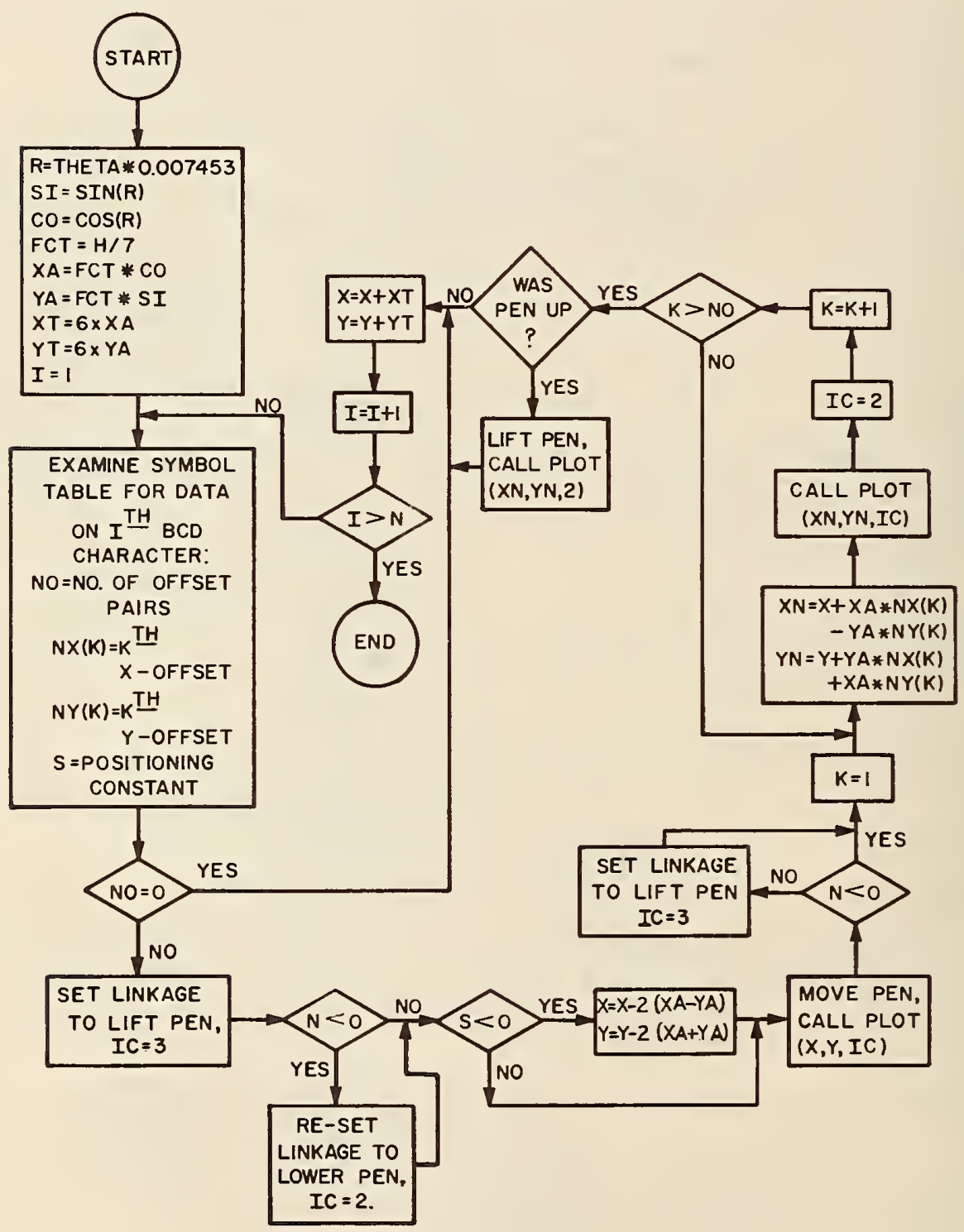

Figure 10 


\section{SEMI BUFFERED IBM 709-7090 TAPE WRITE ROUTINE (TRW2)}

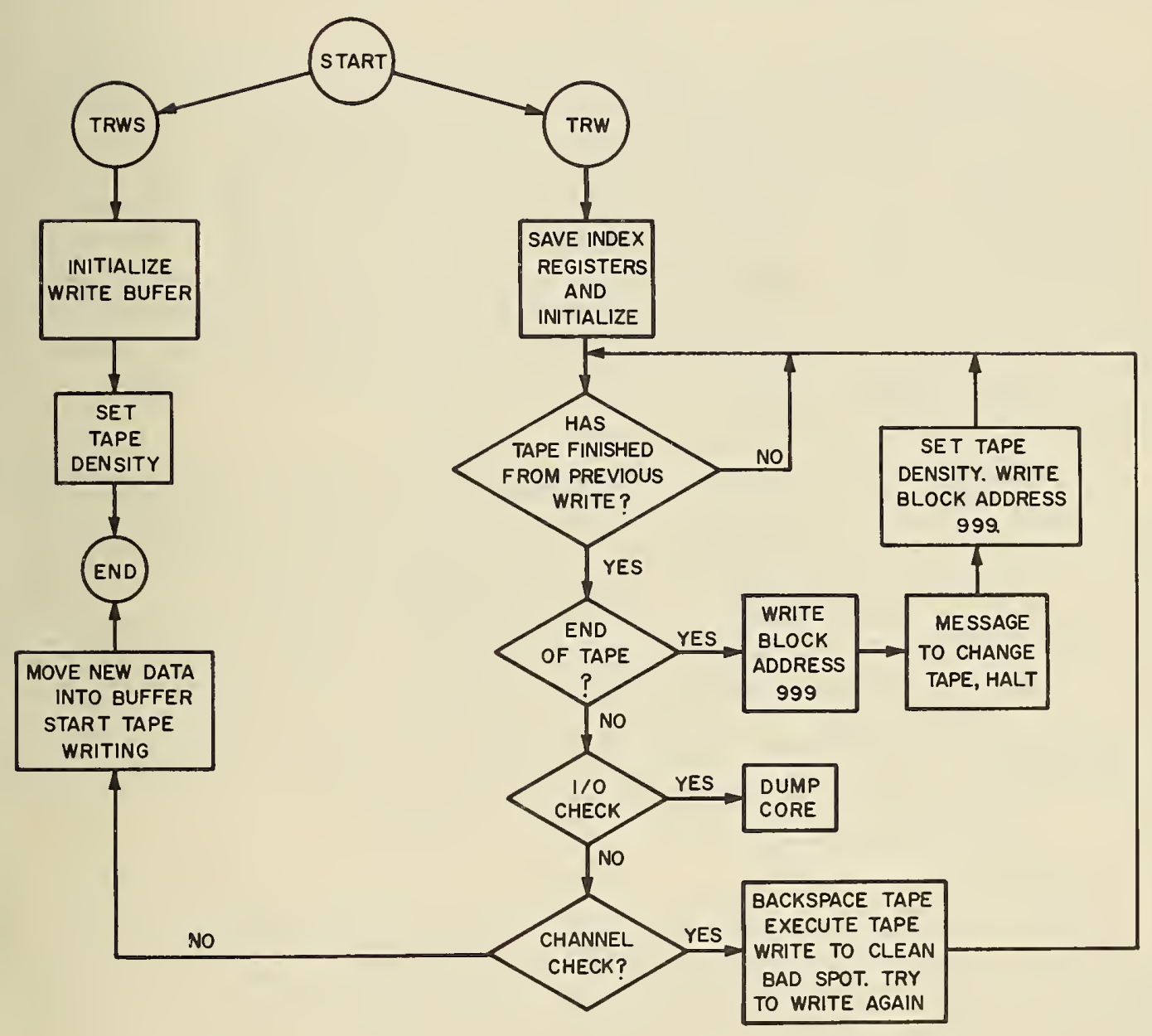

Figure 11 
immediately before the data for that bomb. There will also be an appropriate message before each bomb that has been deleted from the plot tape because it falls outside of U.S. chart limits. Bombs which are deleted because they are duplicates of other bombs do not appear on the printout. Since valuable time is used in forming the print tape and in printing, there should be a real interest in some part of the printout before it is requested.

The output from Part 2 (the sort) is a binary tape containing the same record format as the binary output from Part l except that the records are arranged so that the WAC identification numbers appear in ascending order.

The output from Part 3 is a BCD tape which is used as input for the plot routines in Phase II. The tape is arranged so that there are at least three records for each WAC chart. The first record contains the WAC chart number and the top y value (TY) which is used as a reference point. The second record contains the $x, y$ coordinates of a point and the lethal radii to be plotted around the point. There are additional records for as many more points as appear on that chart. The final record is in the same format but the $\mathrm{x}$ value is set to 99.99 as a flag to indicate the last record for a given chart. To indicate that the last chart has been considered, a dummy chart number is specified with a TY of 99.99.

The primary output from Phase II consists of one or more BCD, low density (200 b. p.i.) tapes. These tapes contain all control and data codes necessary for plotting overlays for targeted WAC chart areas. Figure 12 illustrates the tape format required by the CalComp system. A more detailed description of this format may be found in Reference 4. Another output from Phase II is a computer listing showing the relationship between WAC areas and their location (picture number) on tape. This listing permits the user to select and plot only the areas of interest. The final output of the program consists of the overlays produced on the CalComp 570 system.

\subsection{Operation}

Part 1 of Phase I is run under the NBS Bell Monitor System. The data deck follows the program on the system input tape with the parameter and control cards placed in the manner described in the section on Inputs. Output from Part 1 should be assigned to channel A for efficient entry to Part 2.

Part 2 is the sort from the IBSYS Monitor. The sort control cards are read in on-line from the card reader. The tape to be sorted is mounted on channel A but not readied until the on-line printer instructs the operator as to which unit number to dial. The output will be on channel $B$ with the particular unit being specified on the online printer. 


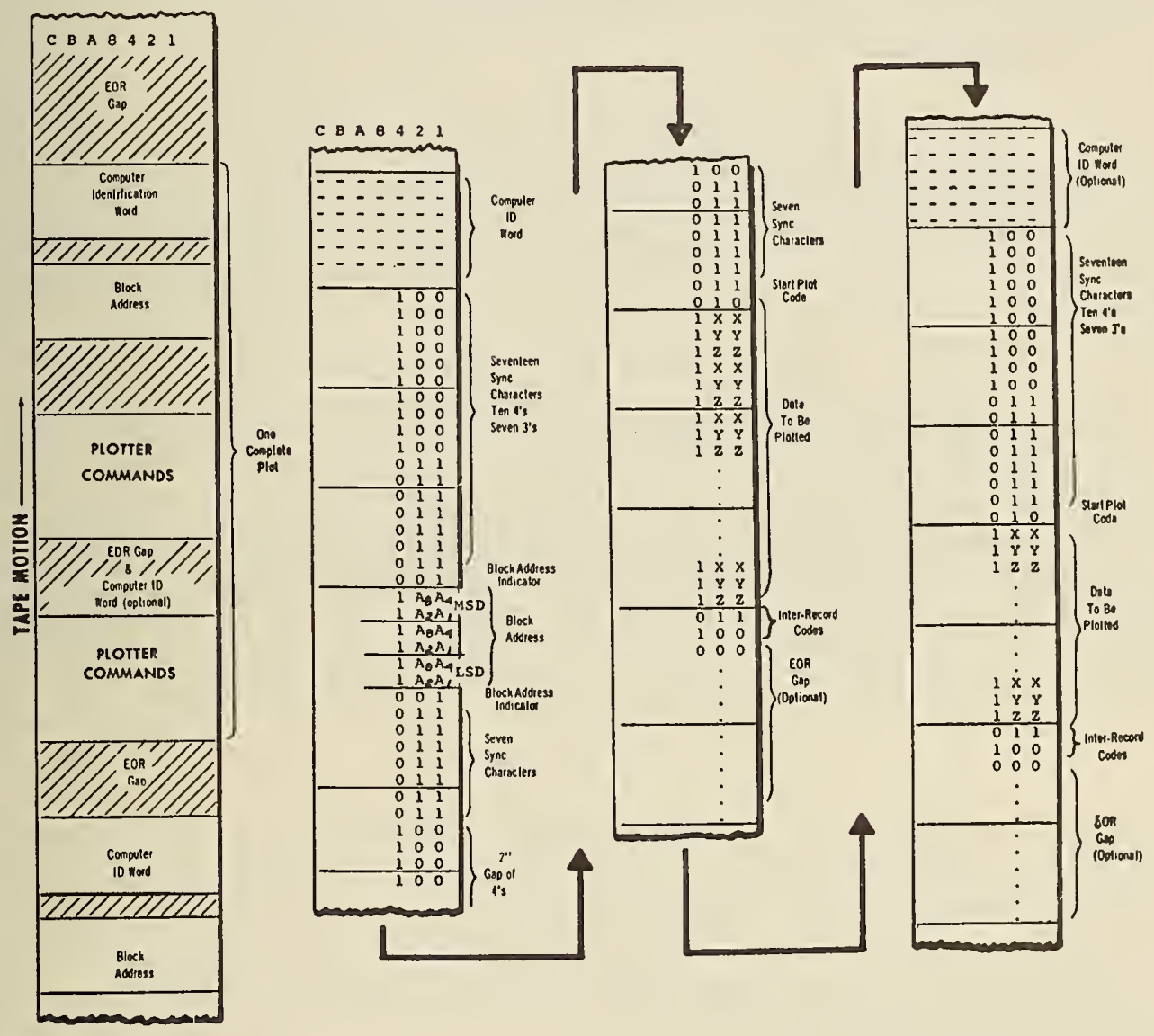

Figure 12 
Part 3 is run under the NBS Bell Monitor System. There are three program tapes which may be assigned to units by the control card described in the section on Inputs. The output from Part 3 should be on channel A for efficient entry to Phase II.

Phase II which also runs under the NBS Bell Monitor System uses only two tape units in addition to the system units. The input should be placed on tape unit A5 and the low density output tape will be written on A6. If more than one output tape is needed, an on-line message will instruct the computer operator to save the tape on unit $A 6$ and to mount a new tape on that unit. All A6 tapes should be labeled and saved for plotting.

When the user has selected the WAC charts which he wants plotted, he needs only to refer to the listing produced in Phase II to determine the tape and picture numbers which contain tliese charts. These numbers should be transmitted with the appropriate tapes to the CalComp operator. The operator should be instructed to position the plotter pen 1 inch from the bottom of the plotter paper before beginning plotting.

When the appropriately labeled overlays have been produced, the user should position them on the WAC charts in the following manner: for WAC chart overlay numbers with a U suffixed, the reference marks (t's) on the overlays should be placed over the charts at the intersections of the upper and middle parallels with the central meridian; for WAC chart overlay numbers with an $L$ suffixed, the reference marks should be placed over the charts at the intersections of the middle and lower parallels with the central meridian.

\section{Future Plans}

As time permits, two refinements should be made to the program. The first is an addition to the circle subroutine to handle the plotting of truncated portions of circles with centers on adjacent overlays. This was discussed in the section on Routines. The second refinement would be mainly for the convenience of the computer operator. Slight reprogramming would make it possible to run all parts of both phases under one monitor system.

\section{Acknowledgements}

The authors want to express their appreciation and thanks to David C. Friedman of NBS for his guidance and direction in assisting them to meet their program objectives.

The authors wish to give particular thanks to Peter S. Shoenfeld of NBS. Mr. Shoenfeld did much of the original work in developing the RLETH subroutine and in developing the algorithm used in the CIRCLE subroutine. Many of his suggestions in the past several months have proved helpful. 
Thanks are also due to Mr. Eugene Kiley, of the Johns Hopkins Applied Physics Laboratory, who was very helpful in checking out the plotter tape control codes.

\section{References}

1. Oscar S. Adams, Lambert Projection Tables for the United States, Department of Commerce, U.S. Coast and Geodetic Survey. Special Publication No. 52, Government Printing Office, Washington, D.C. 1918, pp 5-35.

2. W. J.Erickson and C.F.Schemmerling, Operational and Mathematical Specifications for the Blast Vulnerability Model, System Development Corporation, FN 5746 , August 3, 1961.

3. IBM 7090/7094 Generalized Sorting System, International Business Machines Corporation, Programming Systems Publications, Form C 28-6307-1, May 1963, pp 12-19.

4. James E. Newland and Robert Stomel, Reference Manual SCOOP Programming System for Digital Incremental Plotters, California Computer Products, Inc., November 1963. 


\section{Appendix A - Card Formats}

Data Card Format for Part 1 of Phase I

(Columns other than those specified are ignored by the program.)

Columns

$19-24$

$26-32$

$55-57$

$58-60$

$69-74$

\section{Contents}

Latitude in degrees, minutes, and seconds Longitude in degrees, minutes, and seconds Height of burst in hundreds of feet CEP in hundreds of feet Yield in kilotons

Parameter Cards for Part 1 of Phase I.

\section{Columns}

$1-2$

4

$6-9$

11

\section{Contents}

"NTAP" - Numerical designation of the Part 1 binary output tape. Column 1 designates channel $(0=$ channel $A$, 1 = channel B); column 2 designates the number of the drive on the channel.

"NOUT" - Code for the type of output $0=$ binary tape only

3 = binary tape and $\mathrm{BCI}$ printout

$6=\mathrm{BCI}$ printout only

"XCEP" - Specifies the number of CEP's to two decimal places to be added to the calculated radius. This enables the user to include a probability measure in the calculated radius around the designated ground zero (DGZ).

"NRINGS" - The number of hardness categories for peak over-pressures (PSI values) specified for this run. 
Appendix A (Continued)

Columns

Contents

$14-17$

$20-23$

$26-29$

$32-35$

$38-41$

$44-47$

Card 2

"P(I)" - PSI values of overpressures to one decimal place. From one to six values may be specified beginning with the leftmost field. Unused fields should be left blank.

1

$2-9$

$11-18$

$20-27$

$29-36$

$38-45$

$47-54$

$56-63$

$65-72$

"NH" - Number of altitude categories, each corresponding to a specific height of burst. (While the program is written to accept up to six heights of burst, polynomial coefficients for calculations are currently available only for ground bursts and bursts at 5, 000 feet. If a different altitude is specified on a data card, the program sets the value to 5, 000 feet for calculation purposes.)

"H(K,J)" - Polynomial coefficients for altitude category K. Four coefficients are required for each category; two categories fit on one card. Coefficients presently available appear on the card in the order $\mathrm{H}(1,1), \mathrm{H}(1,2), \mathrm{H}(1,3)$, $H(1,4), H(2,1), H(2,2), H(2,3), H(2,4)$. Since the decimal place and sign may vary among coefficients, it is necessary to punch the decimal point and a sign (a plus sign need not be punched) into the field with the number.

Additional coefficients for more categories would continue in the same format on additional cards. (Column l would be left blank.)

Last Data Card (placed at the end of the data deck)

$69-74$ "000000" - These six zeros indicate a bomb with zero yield and flag the end of Part 1 of Phase I. Because of the way the test is made, it is imperative that a data card never contain a yield of less than 10 kilotons. If it does, the end of the routine will be falsely indicated. 
Control Card for Part 3 of Phase I

(placed at the end of the program deck)

Columns

$1-2$

$3-4$

$5-6$

$7-8$

Columns

$1-2$

$3-4$

$5-12$

$13-16$

$17-20$

$21-24$

$25-28$

$29-32$

$33-36$

\section{Contents}

"NRINGS" - The number of radii to be plotted around each point in this run.

"NTAP" - A two-digit number specifying channel and unit number for the sorted data tape, $0=$ channel $\mathrm{A}, 1$ = channel $\mathrm{B}$.

"IC $\varnothing N "$ - A two-digit number specifying channel and unit number for the tape of WAC constants.

"Kф" - A two-digit number specifying channel and unit number for the output tape to be used in Phase II.

\section{Phase II. Control Card}

(to be placed at the end of the program deck)

Contents

Example

Number of hardness categories. 02 This is equal to the number of circles (maximum of six) plotted around each targeted point.

To print SECRET on each overlay enter 01 ; to suppress printing enter 00 .

Date of run (used for plotting

$05-30-64$ tape identification).

PSI values associated with hard- 05.0 ness categories. The number of 4- 02.5 column fields used equals the number of categories specified in columns 1 and 2 . 


\section{Appendix B - Program Listings}

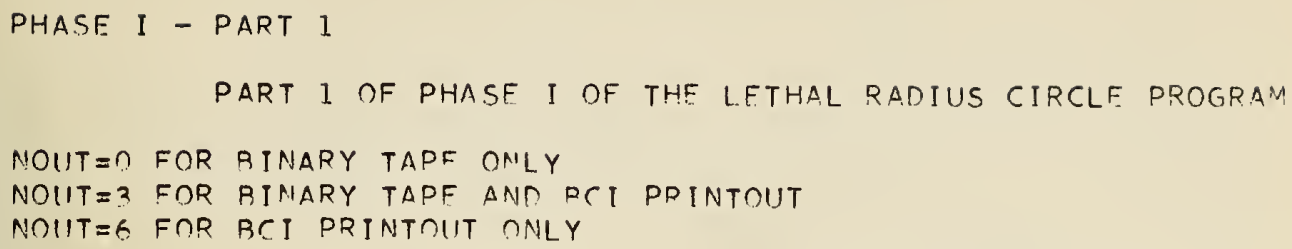




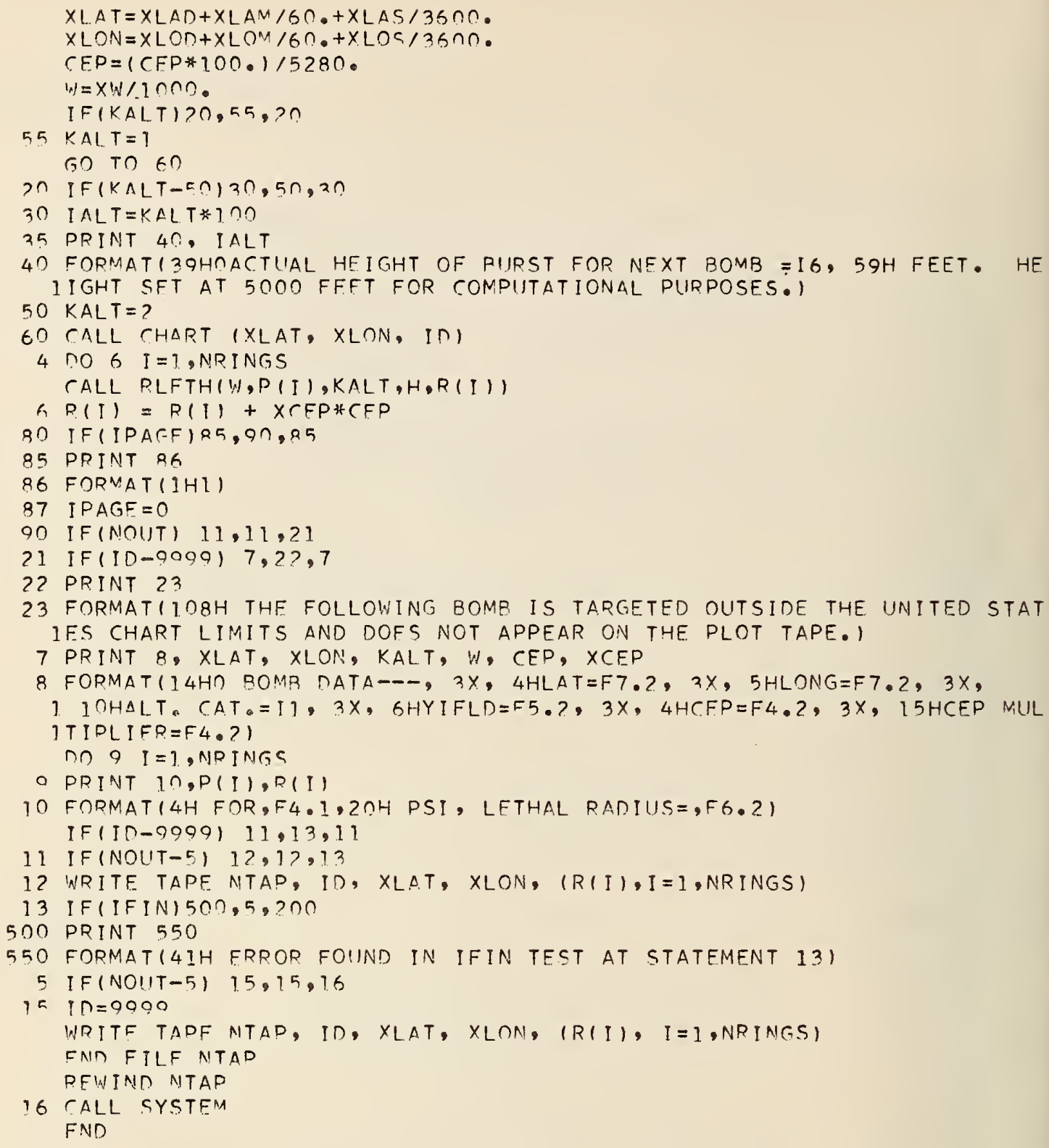


nn 4 I IF (XLAT-n39. Innon, n Inn. n Inn

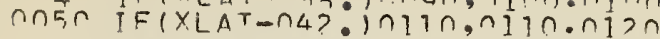

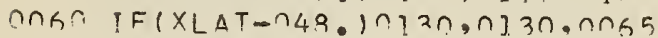

$0 \cap 65$ IF (XLAT-n5n.) In $14 n, \cap 140.16 n n$

On7ก IF(XLAT-028.) InI5n, ก160, ก15n

nnsก IF(XLAT-n34.) InI7n, ก18n, ก18n

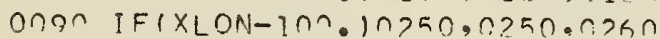

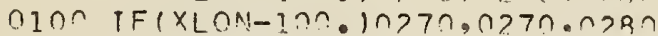

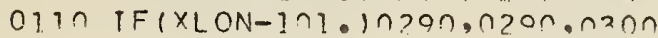

$012 n$ IFIXLON-In1. In $310,0310,0220$

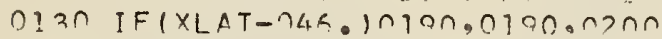

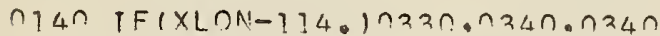

nI5n IF(XLAT-n?F. In15:5, ก??ח.n?3n

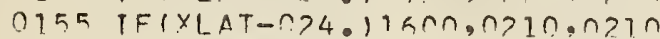

nIRO TFIXLAT-n3n, In>2n, n?4n. n?4n

ก17ก IF(XLON-n04. i3 $50,036 n .0260$

0] $8 \cap$ I $F(X L O N=004.) \cap 37 n, 0380,0280$

nION IF (XLON-nO3.) In $390,040 n . n 4 \cap n$

$0 ? n \cap$ IF (XLON-nO3.) I. $410,0410.042 n$

0? Iก IFIXLON-007. 10420,0440,044n

$07 ? 0$ TF(XLON-097. 10450,0460, ก460

ก?3n TF(XI.ON-nOR.) I. $47 \cap, \cap 480,042 n$

$034 \cap$ IF (XION-OOR. In $40 \cap, \cap 5 \cap \cap, \cap 5 \cap \cap$

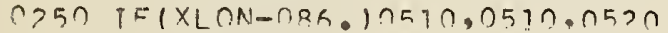

ก) $0 \cap$ PFIXLON-174. In52n,0540,054n

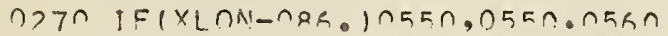

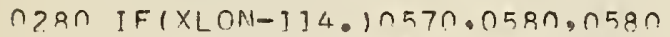

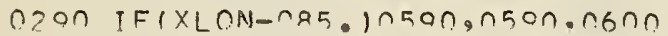

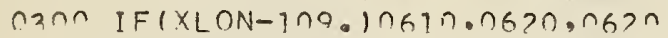

0310 IF(XLON-085.10630,0630.064?

0370 IF (XLON-109.) $1650,0660.0660$

$033 \cap$ TF(XLON-105.10670,0670,06A0

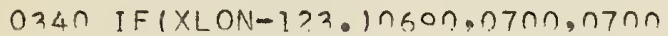

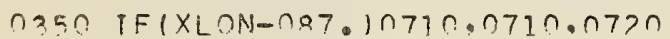

ก36ก IFIXLON-IN9. In72n, ก74n. ก74n

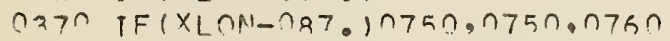

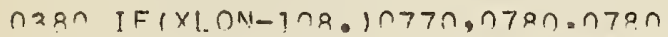

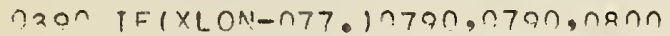

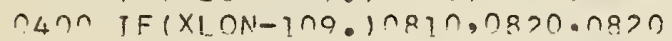

04 In IF $X$ LON-n77. InR2n, ก83n, ก84n

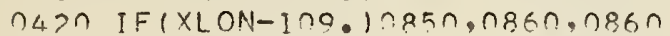

0430 IF $X\lfloor$ LON-O0.5. I0421,0435, 1600

0431 IF (XLON-079.) 1600,0435.0435

$04 ? 5$ ID $=1050$

PFTURN

$044 \cap$ IF(XLON-103.) $7445,0445,160$ ?

0445 in $=1044$

RETURN

O450 TF(XLON-חR5. In451, ก451.15กn

0451 IF(XLON-O70.) 1.5ก0, 0455. 0455

0455 ID $=105]$

RETURN

$046 \cap$ IF (XLON-103.) ก 465, 0465, 150ก

0465 ID $=1045$

RFTURN

0470 IF (XLON-0ON. IOR65,0855, กR7n

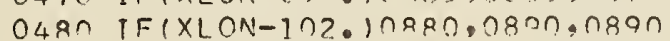

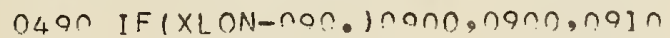

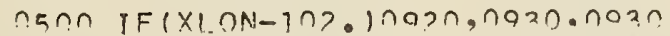

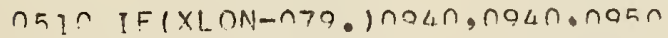

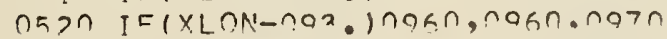

ก5xก IFIXLON-107. Inosn, noRn, noon

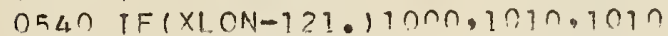

$055 n$ IF (XLLN-n79.) In?ก, I0?ח, 103n

$056 \cap$ IF (XLON-092.) In4n. In 40.1050 


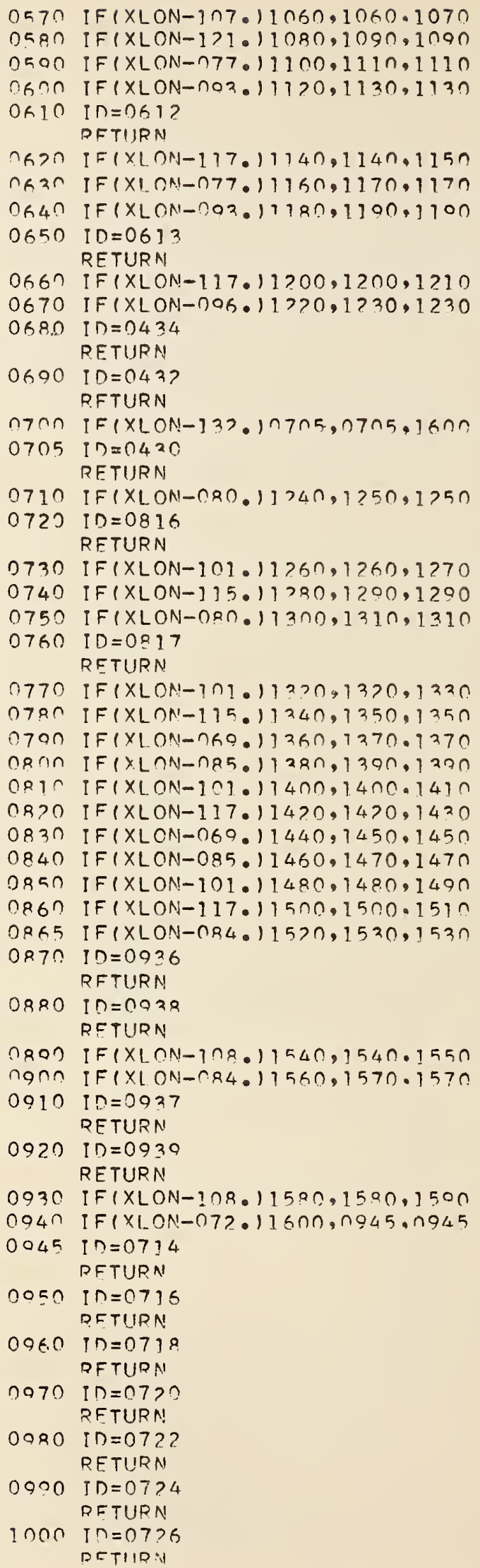




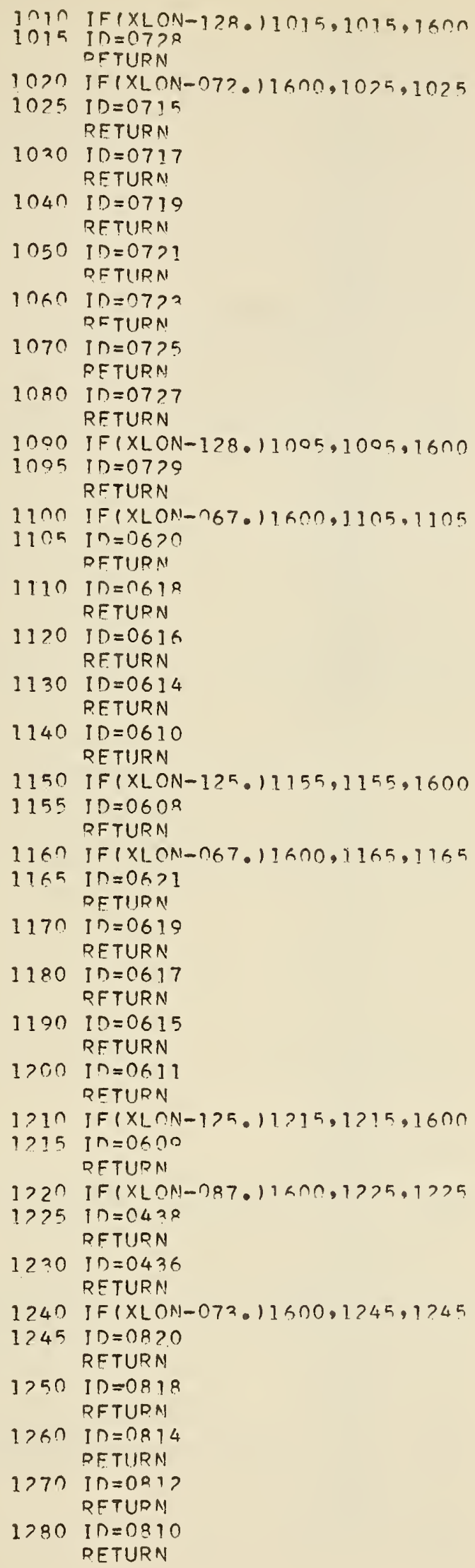




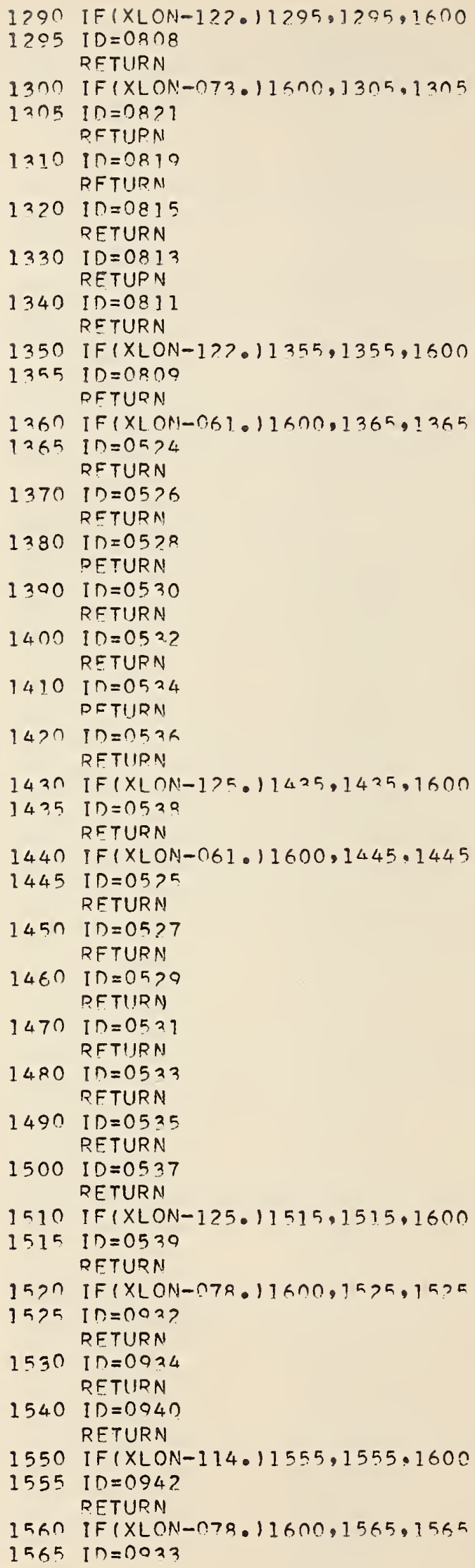


PHASE I - PART 3

ROIITINE TO CONVERT GEODETIC POSITIONS AND RADII TO PLOTTER INCHES NMAPS $=0$

75 READ TAPE NTAP, ID, XLAT, XLON, (R(I), I = I, NRINGS)

200 READ TAPF ICON, IWAC, CM, FLRU, TY, RL, PL

205 IF (IWAC-ID) 200, ?10,900

210 NMAPS $=$ NMAPS +1

400 IMAP $=I \Pi / 2$

IMAP $2=I M A D *$ ?

ITFST $=$ ID-IMAP

450 IF(ITFST) ]500,500,550

500 WRITE OUTPUT TAPF KO, 510, IMAP, TY

510 FORMAT (3HWACI3, 1HL, 1X, F5.2)

GO TO 250

550 WRITE OUTPUT TAPE KO, 560, IMAP, TY

560 FORMAT (3HWACI3, IHU, IX, F5.2)

$250 \quad A N G=(C M-X L O N) * 0.6205$

SANG $=$ SINF $(A N G * 0.01745)$

$R P=R L-((X L A T-P L) * P L R U) / 2$.

$C A N G=C O S F(A N G * 0.01745)$

$X C X=R P * S A N G$

$X C Y=R L-(R D * C A N(7)$

$C X=(X C X * 20.37) / 1000000$.

$C Y=(X C Y * 30.37) / 10 n n 0 n n$.

DO $300 \quad I=1$, NRINGS

$300 R(I)=R(I) * 0.06326$

WRITE OUTPUT TAPF KO, 610, $C X, C Y,(R(I), I=1, N R$ INGS)

6) O FOPMAT(F6.?,11F5.?.)

100 READ TAPE NTAP, ID, XLAT, XLON, (R(I), I=1, NRINGS)

650 IF(IWAC-ID)70ก, 250, 1000

$700 \times X=99.90$

IIRITF OITPUT TAPF KO, 610, $C X, C Y,(R(I), I=1, N R I N G S)$

750 I F (IN-9000)? $00,17 n 0,8 \cap n$

RกO DRINT 850

850 FOPMAT15OHOPROGRAM STOPPED WHFN IMAC GREATFR THAN ID AT STATEMENT

17501

GO TO 1700

900 PRINT 950

950 FORMAT 159 HOPROGRAM STOPPED WHFN IWAC GRFATFR THAN ID AT STATEMENT

12051

GO TO 1700

1500 PRINT 1600

1600 FORMAT 159 HOPROGRAM STOPPFD WHFN ITFST FOUNO NFGATIVF AT STATFMENT 14501

(3) TO 1700

$1000 \quad C X=99.90$

WRITF OUTPUT TAPF KO, 610, CX, CY,IR(I), I=1,NRINGS) PRINT 1200

1200 FORMAT (5OHOPROGRAM STOPPED WHEN IWAC GREATER THAN ID AT STATEMENT

16501

1700 TY $=99.99$

IMAP $=0$

WRITE OUTPUT TAPE KO, 175n, IMAP, TY

1750 FORMAT (3HWACI 3 , 1HX, 1X, F5.2)

WRITE OIITPIT TAPE KO, 1800 , NMAPS

1 IOO FOPMAT (4OH TOTAL NUMRFR OF OVFPLAYS FOR THIS RUN $=1 X, 121$

FND FILF KO

RFWIND KA

R.FWIND ICON

REWIND NTAP

2000 CALL SYSTEM

FND 
MAIN PROGRAM

PHASE II OF LFTHAL RADIUS PLOT PROGRAM

MIMFNSTON DATA $(7000), R(6), P S T(6), X M A P(2), M(3000)$

COMMON ITAPE

12 FORMAT (2I2,A6, $12,6 A 4)$

14 FORMAT (AG,A), $1 X, F 5.2)$

16 FORMAT (F6.2,7F5.2)

18 FORMAT $(1 H 1, A 6, A 2)$

20 FORMAT (42HOWAC NUMBER - PICTURE NUMBER - TAPE NUMBER)

22 FORMAT $(2 \mathrm{H}$ A6, A1,10X,13,13X, I1)

$I T A P F=1$

I $P$ ICT $=1$

(ALL PLOTSIDATA 3000$), 3000)$

RFAO 12, NRINGS, TSFC,DATE(1), DATF (2), (PSI (JJ), JJ I, NRINGS) PRTNT 19, חATF(1), IATF(2)

$P R$ INT $2 \cap$

10 RFAD INPUT TAPF 5,14,XMAP(1),XMAP(2), TY

IF (TY-OO. ПO) 11,99,99

11 PRINT 22, XMAP(1), XMAP (2), IPICT, ITAPE

CALL CYMBOL $(0,0,0.0,007,3,0,0,-1)$

40 CALL SYMROL $(-.8,-.8,-.28, X M A P(1), 0.0,7)$

IFIISFC) $50,50,45$

45 CALL SYMBOL $(1.2,-.8, .29,6 H S E C R F T, 0.0,6)$

$5 \cap$ CALL SYMROL $(0, \cap, T Y, \cap \cap 7,3, \cap, \cap,-1)$

71 RFAD INPUT TAPE $5,16, C X, C Y,(R$ (LL), LL=I, NRINGS)

I $F(C X-90, \cap \cap) 75,25,25$

75 CALL PLOT $(C X, C Y, 3)$

CALL PLOTICX,CY,?)

90 DO 23 IR $=1$, NRINGS

FRSTX $=(X+R(I R)$

CALL PLOT (FRSTX, CY,3)

CALL PLOTIFRSTX,CY, 2$)$

CALL CIRCLF(CY,R (IR), M, NUMB)

CALL SYMROL (FRSTX, CY, - 14,PSI (IR),90,0,4)

23 CONTINUF.

GO TO 71

25 CALL PLOT(36.0,0.0,-3)

IPICT $=I P I C T+1$

GO TO 10

99 REWIND 5

REWIND 6

CALL SYSTEM

END

$\begin{array}{lll}* & \\ \text { * } & \text { LABEl } \\ \text { *PLOT2 } & \text { FAP } & \\ & \text { COUNT } & 340 \\ & \text { FNTRY } & \text { PLOT } \\ & \text { FNTRY } & \text { PLOTS } \\ & \text { ENTRY } & \text { CONVPT }\end{array}$




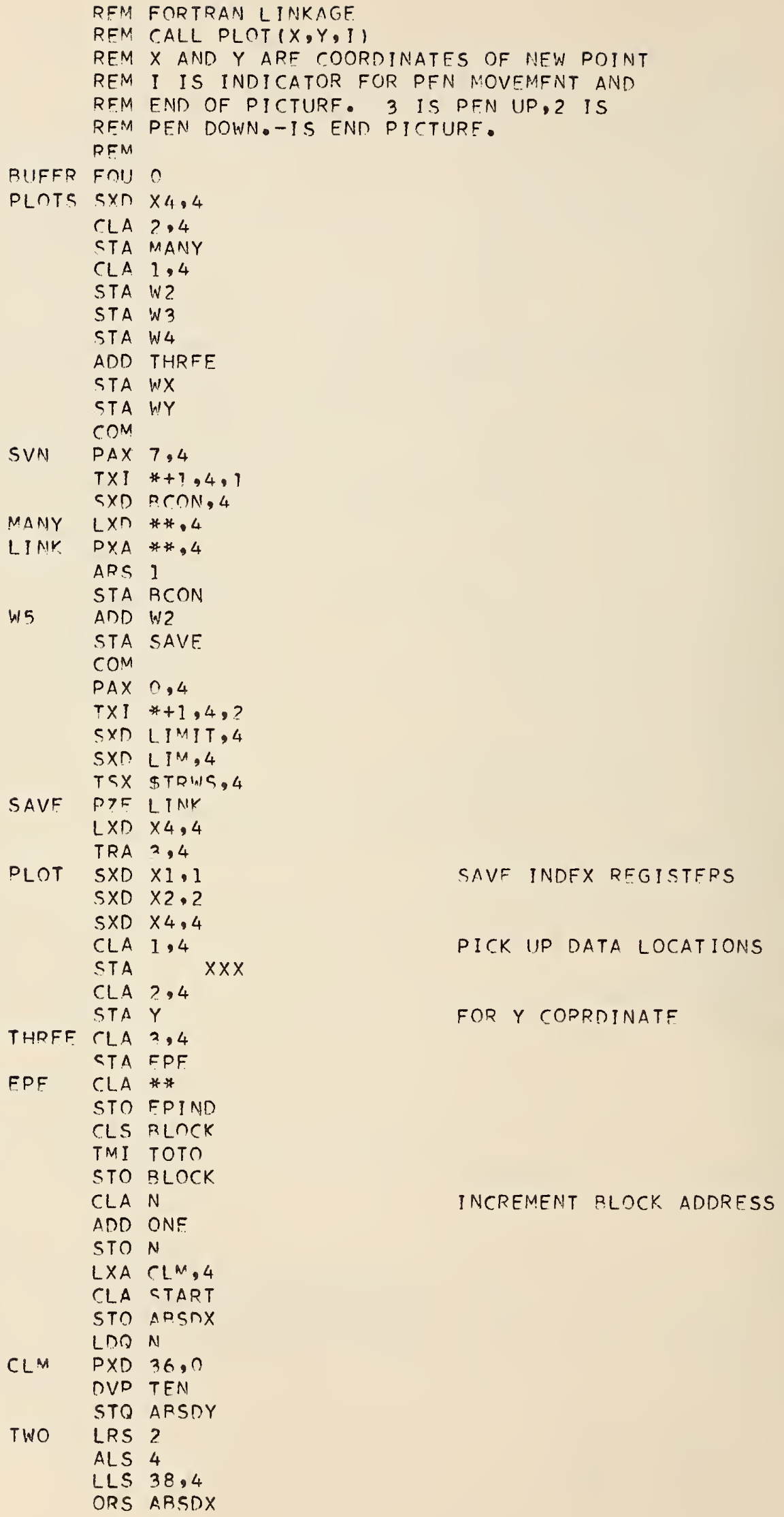




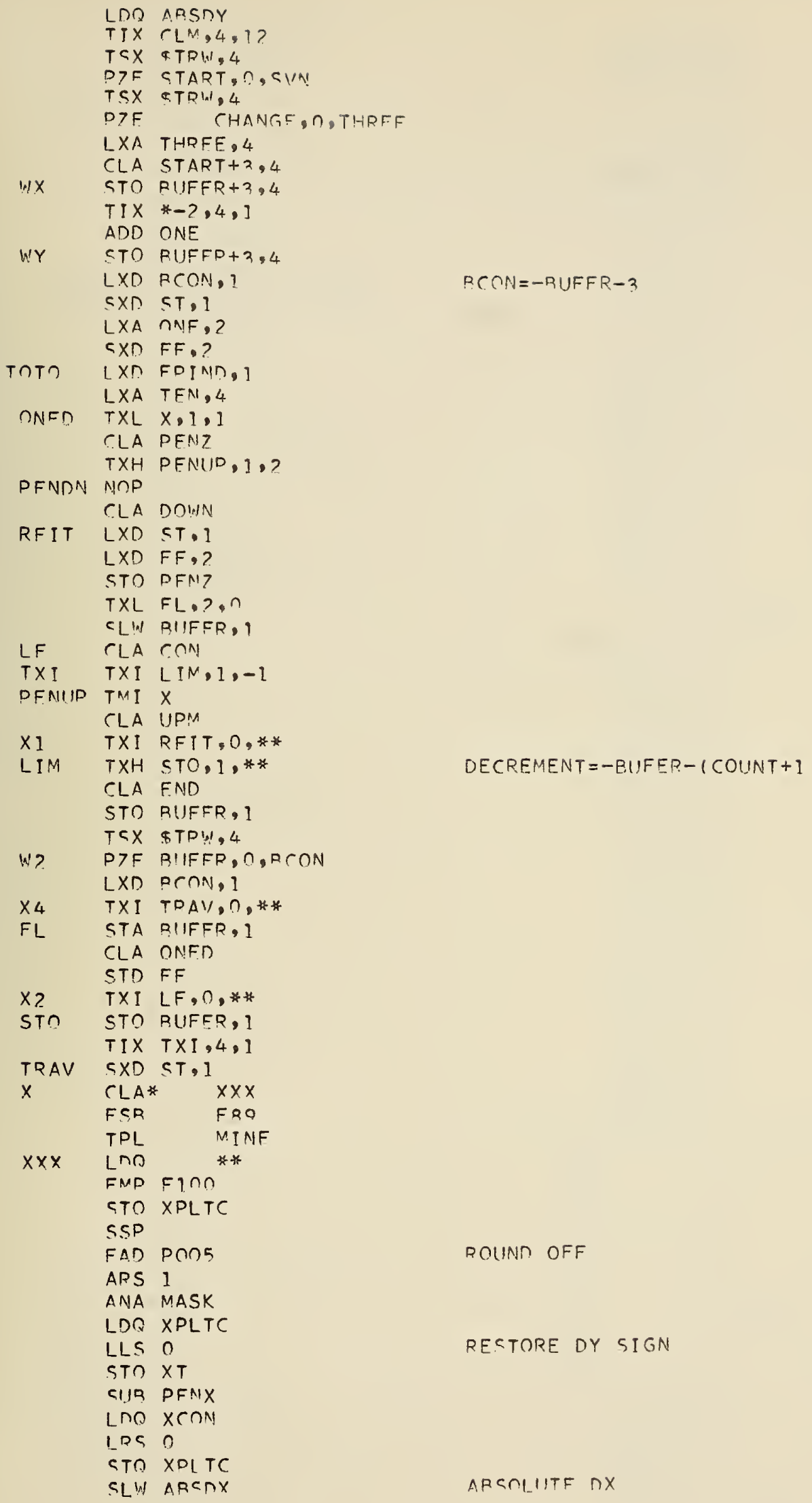




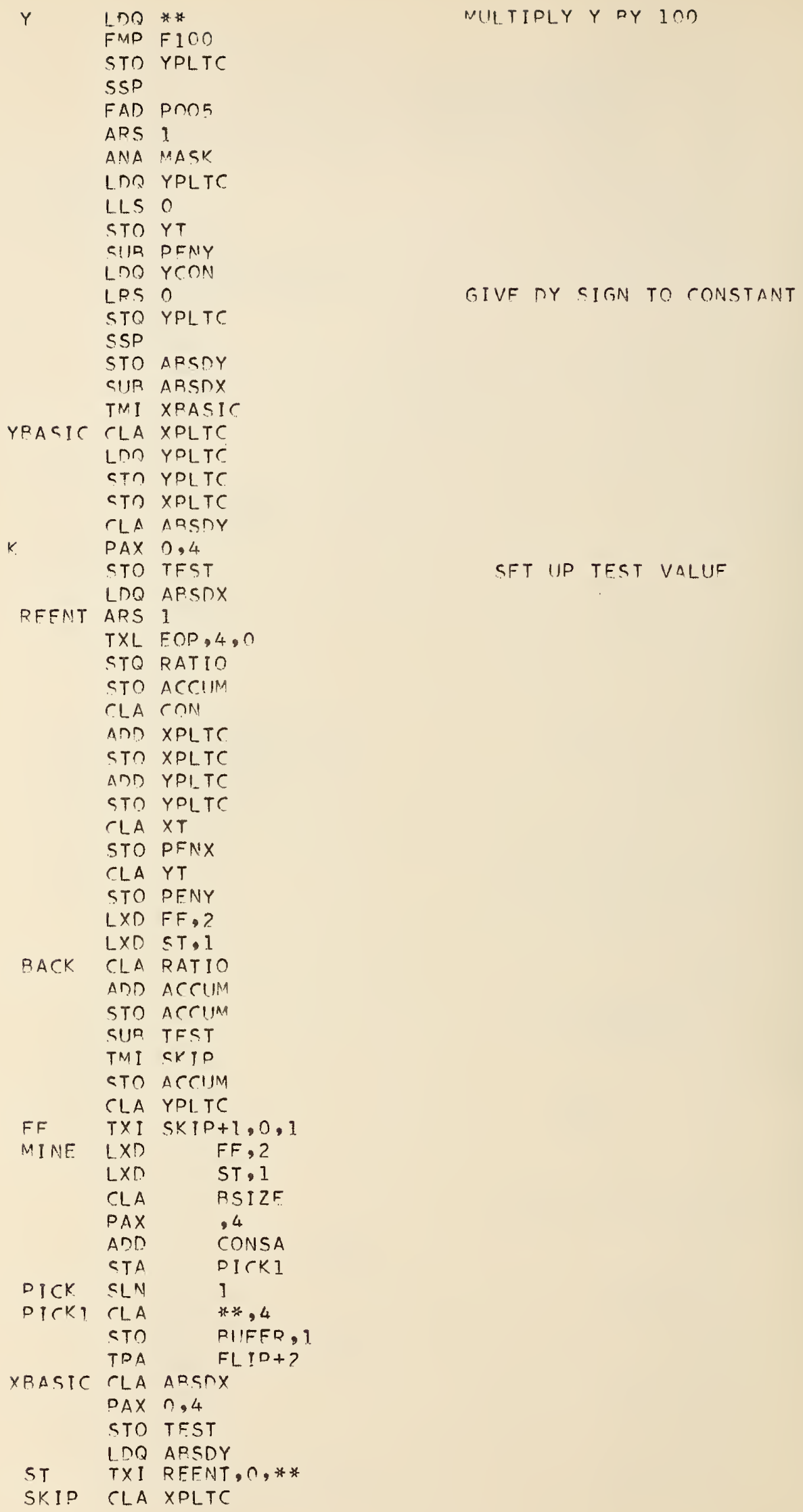




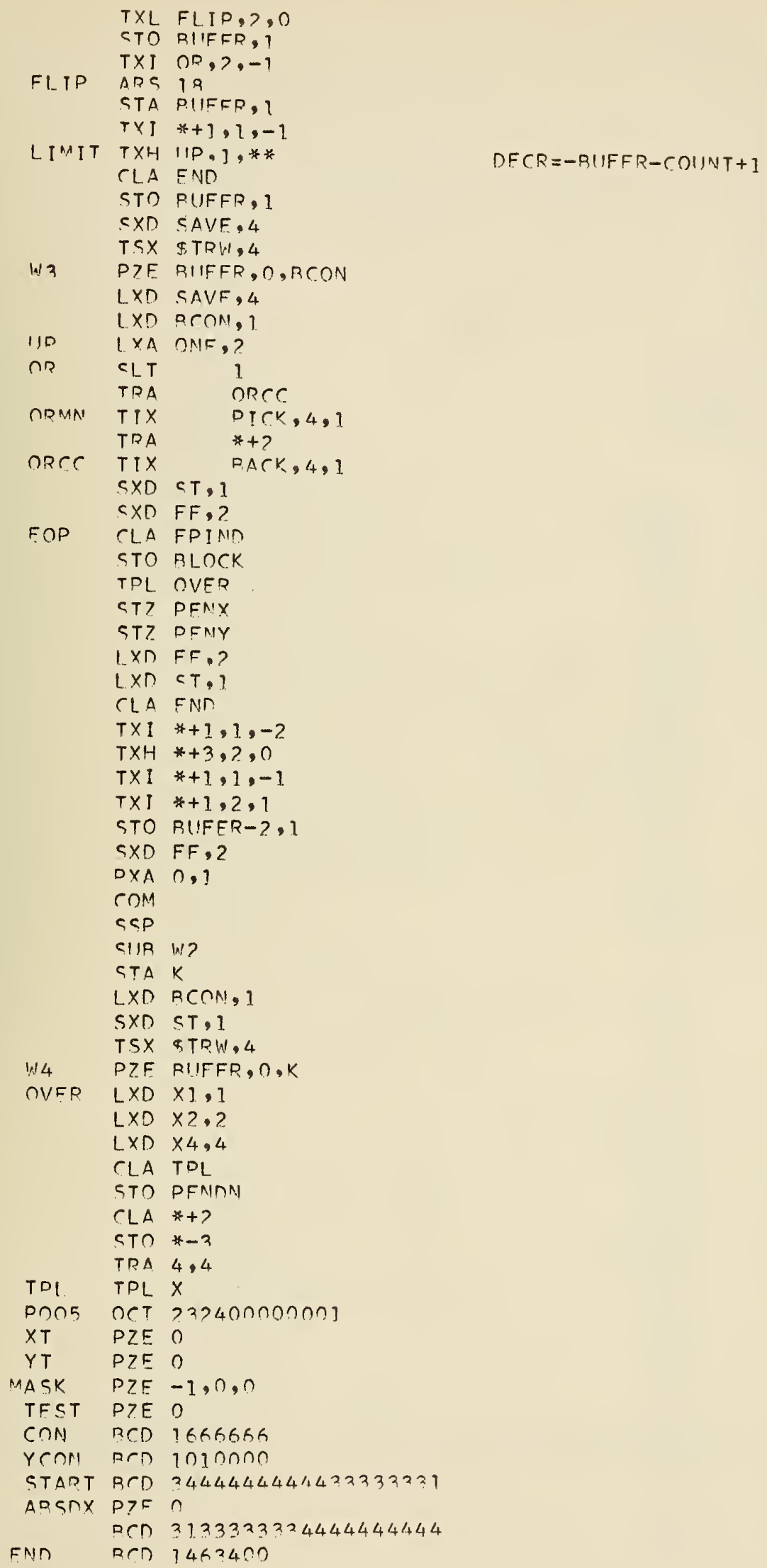




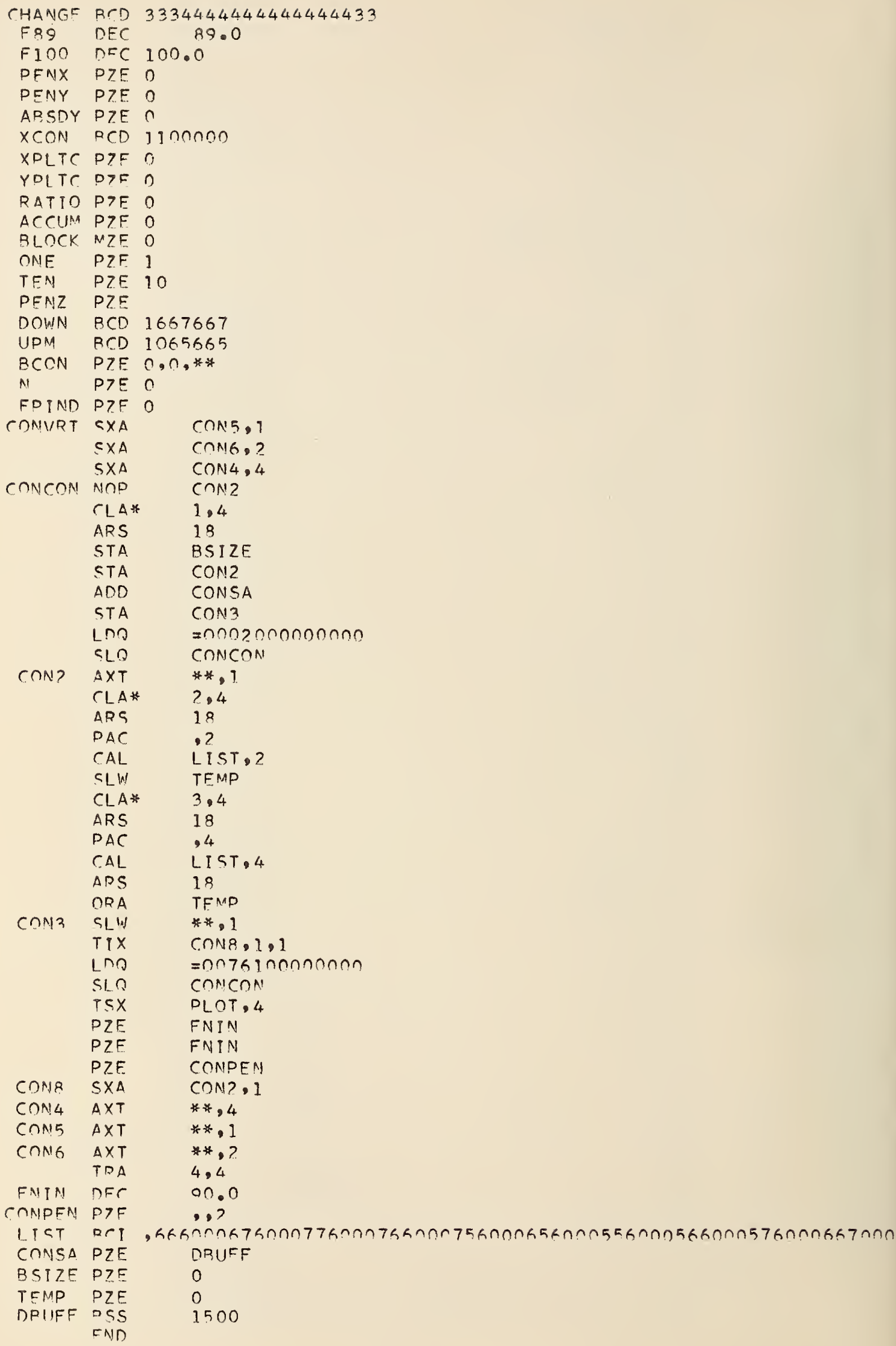


FORTRAN LINKAGF

CALL CIRCLEICY,R,M, NUMP)

$C Y=C E N T F R$ Y COORDINATF OF CIRCLF. $R=R A D I U S$

M AND NUMP ARE OUTPUTS

SUIRROUTINE CIRCLEICY,R,M, NUUMR)

DIMENSTON M(3OOO)

$I=0$

EN口SW $=$ ?

$X=P$

$Y=0$

$R S \cap=R * *$ ?

$X S \cap=R S O$

$Y S Q=0$

$1 \quad I=I+1$

BOUND $=C Y+Y$

I $F(X) 2,2,4$

2. IF $(Y) 7,7,3$

$3 N Q=3$

GO TO \&

4 I $F(Y) 5,6.6$

$5 \quad N \cap=7$

Gก TO 8

$6 \mathrm{NO}=1$

GO TO 8

$7 N Q=5$

8 IF $(A R S F(X)-A P S F(Y)) 00,90,9$

9 $N Z=0$

GO TO 91

$90 \quad N Z=1$

१1 $D F L=X S Q+Y S Q-R S O$

$N Z O=N Z+N O$

GO TO(10,20,3n,40,50,60,7n, $2 \cap), N ? 0$

10 [F (FNOSW) 99,1$], 99$

QO $M(I)=$ ?

NUMAR $=I / 2$

$K=I-1$

no $37 \quad I=1, k, 2$

$J=I+1$

37 CALL CONVRT (NUMB,M(I),M(J)) RETURN

11 TF(DEL) 13,13,1?

12 IFIROUND-9.5) I4,14,15

$14 M(I)=8$

GO TO 16

I5 $M(1)=7$

$16 x<0=x<0-. \cap ? * x+.0 \cap 01$

$X=X-.01$

?? $Y \subset \cap=Y \subset \cap+.07 * Y+. \cap \cap \cap 1$

$Y=Y+. ?$ ?

GO TO 1

13 IF (ROUND-9.5)17,17,18

$17 M(I)=1$

GO TO 2?

$18 M(I)=0$

Gก TO 2?

?0 IF (DFLI;?, 1?,? ?

2. $M(I)=7$

GO TO 45

40 IF (DFL)? 1,? 1, 41

41 I $F(R O U N D-0.5) 42,42,43$

$42 M(I)=6$

GO TO 44 


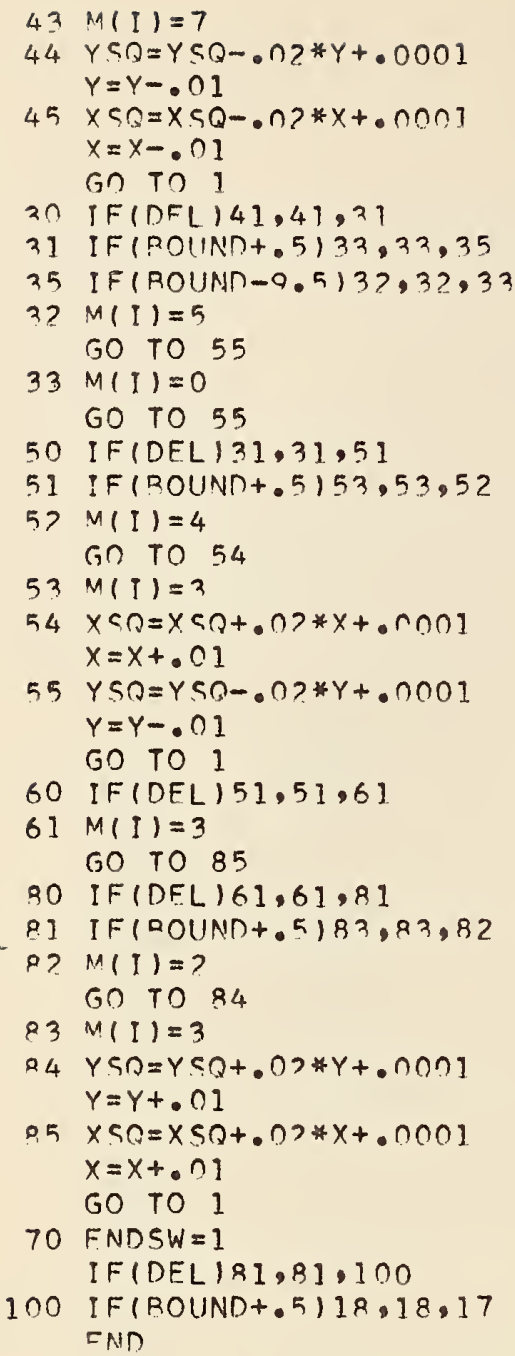

\section{SURPOITTINE MSG}

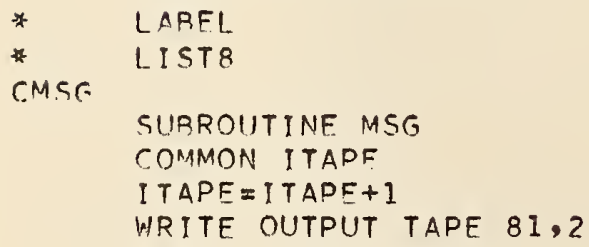

2 FORMAT $152 \mathrm{H}$ REMOVE TAPE ON A-6 AND MOUNT NEW TAPE. PRESS START ) WRITE OUTPUT TAPE 81,3

3 FORMAT $147 \mathrm{H}$ RETURN ALL REELS WRITTEN ON A-6 TO PROGRAMMER. RFTURA FNT 
SUBROUTINE SYMBOL

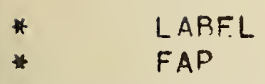




\begin{tabular}{|c|c|c|}
\hline & REM & \\
\hline & $C L A$ & 5,4 \\
\hline & $\begin{array}{l}\text { STA } \\
\text { REM }\end{array}$ & TH \\
\hline & CLA & 6,4 \\
\hline & STA & $N N$ \\
\hline$N N$ & CLA & ** \\
\hline & STO & $x \times K$ \\
\hline & TMI & SPECL \\
\hline 7. FRO & $P D X$ & 0,1 \\
\hline & LXA & $36 \mathrm{~N}, ?$ \\
\hline LRTN & CLA & $L_{3}$ \\
\hline RTN & $\begin{array}{l}\text { STD } \\
\text { PFM }\end{array}$ & VL \\
\hline $\mathrm{TH}$ & $\angle D Q$ & $\# \#$ \\
\hline & FMP & CONST \\
\hline & STO & INCC \\
\hline & TSX & $\$ S I N, 4$ \\
\hline & LRS & 35 \\
\hline & FMP & FACT \\
\hline & STO & INCS \\
\hline & CLA & INCC \\
\hline & $T S X$ & $8 \cos , 4$ \\
\hline & LRS & 35 \\
\hline & FMP & FACT \\
\hline & STO & I NCC \\
\hline & REM & \\
\hline & $\angle D Q$ & INCC \\
\hline & FMP & F6 \\
\hline & STO & $X T$ \\
\hline & LDQ & INCS \\
\hline & FMP & F 6 \\
\hline & STO & $Y T$ \\
\hline & RFM & \\
\hline & $L \times A$ & ZFPn, 4 \\
\hline $\operatorname{lnC}$ & LDO & $* * 4$ \\
\hline & LGL & $42 \cdot 2$ \\
\hline VAR & $T \times I$ & $*+1,0,0$ \\
\hline & ANA & $63 R 35$ \\
\hline & COM & \\
\hline & $S \times D$ & $1 \times \cdot 1$ \\
\hline RFENT & $S \times D$ & $2 \times \cdot 2$ \\
\hline & $5 \times D$ & $C O M, 4$ \\
\hline & PEM & \\
\hline Fin & PAX & $-1 \cdot 1$ \\
\hline & CLA & TARLF-1, 1 \\
\hline & STA & OLOC \\
\hline & STA & $O L O C$ \\
\hline & ARS & 6 \\
\hline 63835 & PDX & 63,1 \\
\hline & ARS & 12 \\
\hline & ANA & 63835 \\
\hline & STO & NO \\
\hline & TZE & CLAP \\
\hline & CLA & $X \times K$ \\
\hline & TPL & $D L O C-1$ \\
\hline & RFM & \\
\hline & CLA & INCS \\
\hline & $F \subseteq R$ & INCC \\
\hline & $A C L$ & TWTCF \\
\hline & FAD & $x \cap$ \\
\hline & STO & $\times 0$ \\
\hline & CLS & INCC \\
\hline & F SR & I NCS \\
\hline & $A C L$ & TWICE \\
\hline
\end{tabular}

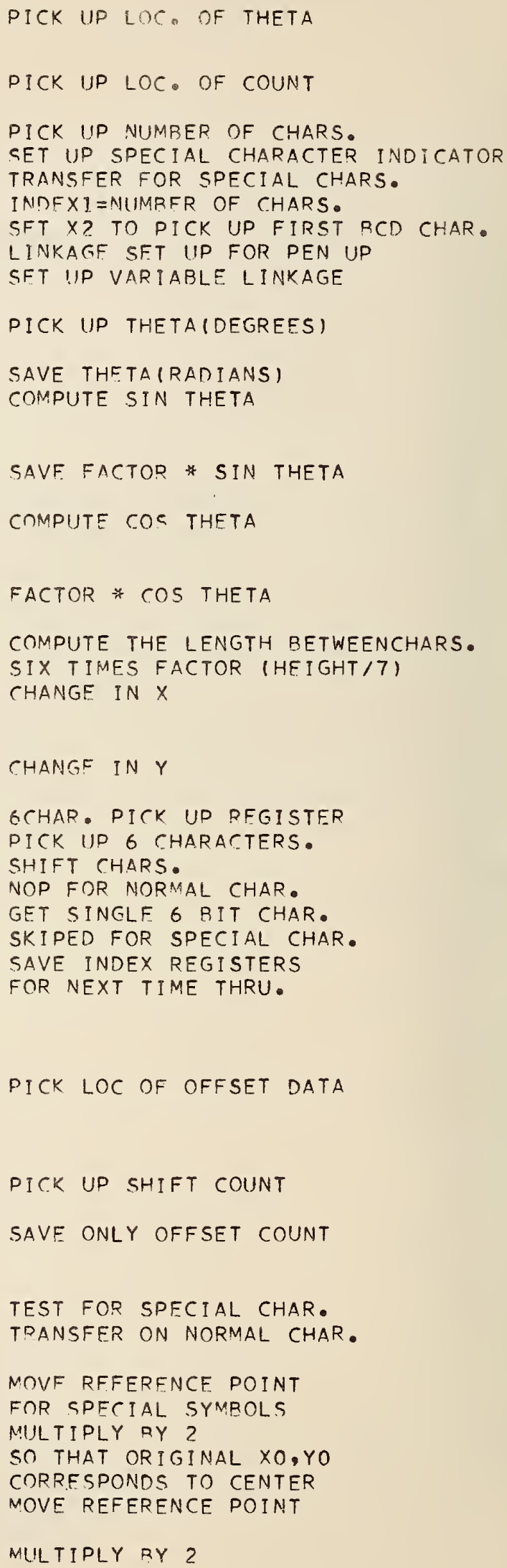


FAD YO

STO YO

RFM

LXA ZERO,?

OLOC LISS **?

LGL 39,1

ANA 7R25

PAX 0,4

RFM

TXL $* 3,4,6$

CLA L 3

X TXI STD, ก, **

REM

CLA $X O$

STO $X X$

CLA YO

ETO YY

REM

TXL OLOC, 4, 0

RFM

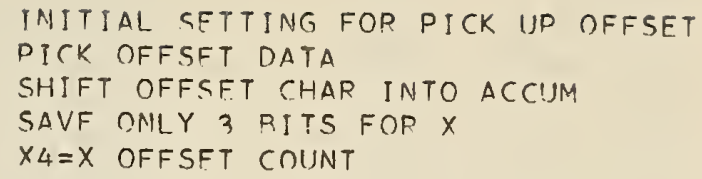




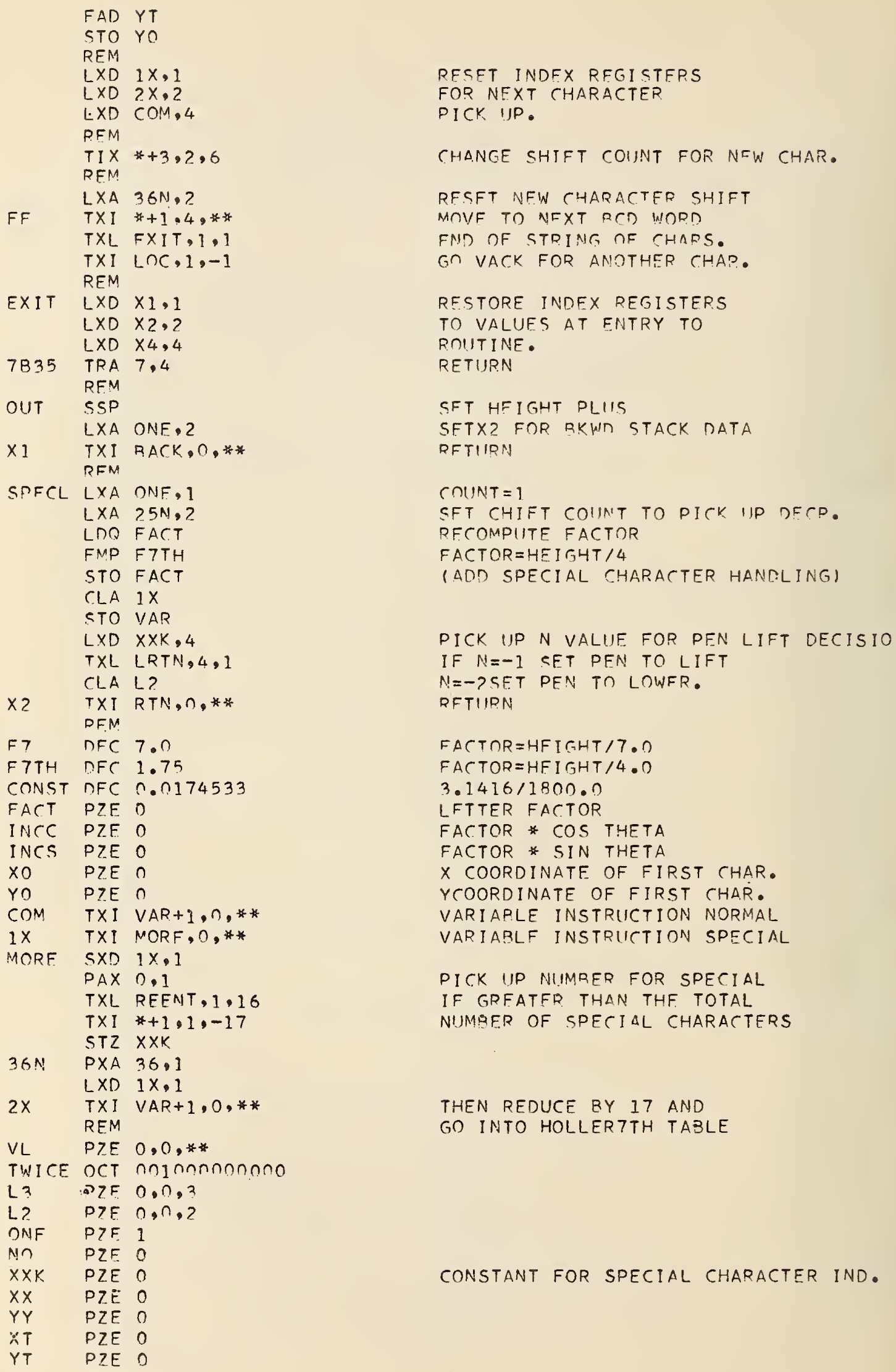


P7.E $\$ 4,0,64 * 30+12 \quad-13$

PZE S11, $0,64 * 30+14 \quad-11$

PZE $\$ 10,0,64 * 30+7 \quad-10$

PZE $59,0,64 * 36+8 \quad-9$

PZE $58,0,64 * 30+6 \quad-8$

PZE $57,0,64 * 36+7 \quad-7$

PZE $\$ 6,0,64 * 36+7 \quad-6$

$P>E$ S5, $0,64 * 30+7 \quad-5$

P7F. $\$ 4,0,64 * 30+7 \quad-4$

P>E $\$ 3,0,64 * ? 4+6 \quad-3$

PYE S?,0,64*18+1? -?

$P 7 E \leqslant 1,0,64 * ? 4+8 \quad-1$

TARLF PZF $0,0,64 * 24+0$ ก0

$P>F . N 1,0,64 * 18+5 \quad 01$

PZE N?, 0,64*24+8 O?

PZE N3.0,64*24+13 O3

PZE N4,0,64*30+9 04

PZE N5,0,64*6+9 05

PZE. NG, 0,64*24+11 06

PZE N7,0,64*36+6 07

$P Z F \quad N 3,0,64 * 2.4+17 \quad 10$

PZE N9,0,64*1R+12 11

P>E CNLON, $0,64 * 24+111 ?$

PZE MINUS, $0,64 * 12+5 \quad 13$

PZE MINUS, 0.64*17+8 14

PZF LF, 0,64*24+6 15

PZE N7,0,64*12+8 16

PZE N?+1,0,64*]2+4 17

PZE PLUS, $0,64 * 12+5$

PZE A, $0,64 * 36+10 \quad 21$

PZE D+1,0,64*30+12 ?2

$P Z E \quad 0,0,64 * 24+8 \quad 23$

$P \geq F=0,0,64 * 6+7 \quad 24$

$P>E L, 0,64 * 30+7 \quad 25$

P?F $L, 0,64 * 24+6 \quad 26$

P>F $6,0,64 * 18+17 \quad 27$

PZF $\mathrm{H}, 0,64 * 36+6 \quad 30$

PZE RP, 0,64*12+6 31

$P Z E N 2+1,0,64 * 24+4$

PZE N7,0,64*12+5 33

PZE RP, $0,64 * 30+4$

PZE AR, 0,64*18+5 35

PZE MINIJS, 0,64*30+8 36

P>E AST, $0,64 * 24+3 \quad 37$

$P>F$ MIN!II, $0,64 * 30+2 \quad 40$

$P>E U, 0,64 * 17+5$

P7E M, 0,64*19+7 4?

P7E L, $0,64 * 30+3 \quad 43$

PZE $M, 0,64 * 36+5 \quad 44$

PZE N, 0,64*18+4 45

PZE $0,0,64 * 36+11 \quad 46$

PZE W, 0,64*18+7 47

PZE $0,0,64 * 7,4+11$

PZE W, 0,64*18+10 51

PZE PER, 0,64*36+14 5?

$P>E \quad N 7+1,0,64 * 6+11$

P>E AST, 0,64*1?+11

$P>F \mathrm{~N} I, 0,64 * 2,0+5 \quad 55$

P? $T, 0.64 * 12+5 \quad 56$ 


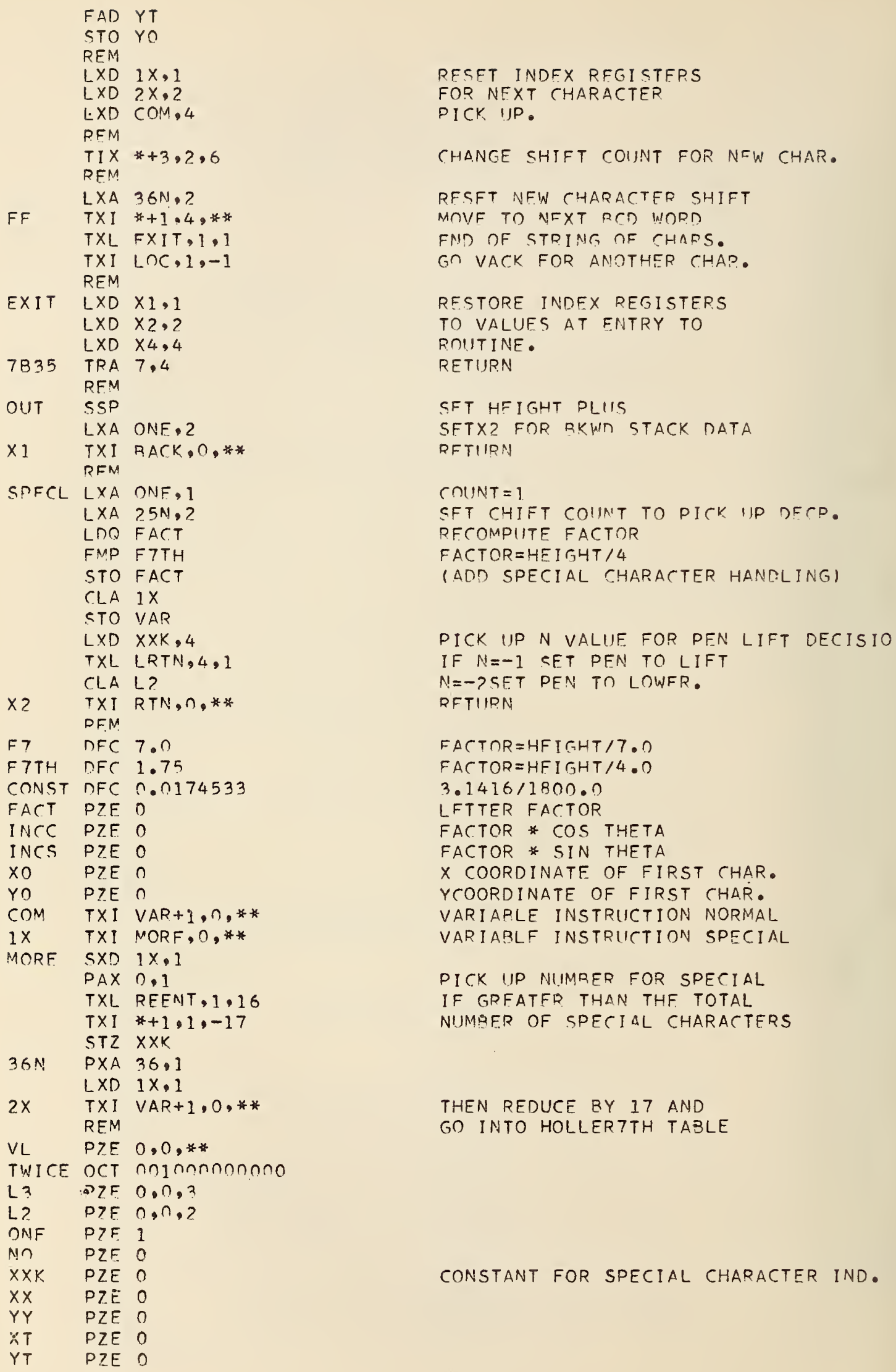


P7.E $\$ 4,0,64 * 30+12 \quad-13$

PZE S11, $0,64 * 30+14 \quad-11$

PZE $\$ 10,0,64 * 30+7 \quad-10$

PZE $59,0,64 * 36+8 \quad-9$

PZE $58,0,64 * 30+6 \quad-8$

PZE $57,0,64 * 36+7 \quad-7$

PZE $\$ 6,0,64 * 36+7 \quad-6$

$P>E$ S5, $0,64 * 30+7 \quad-5$

P7F. $\$ 4,0,64 * 30+7 \quad-4$

P>E $\$ 3,0,64 * ? 4+6 \quad-3$

PYE S?,0,64*18+1? -?

$P 7 E \leqslant 1,0,64 * ? 4+8 \quad-1$

TARLF PZF $0,0,64 * 24+0$ ก0

$P>F . N 1,0,64 * 18+5 \quad 01$

PZE N?, 0,64*24+8 O?

PZE N3.0,64*24+13 O3

PZE N4,0,64*30+9 04

PZE N5,0,64*6+9 05

PZE. NG, 0,64*24+11 06

PZE N7,0,64*36+6 07

$P Z F \quad N 3,0,64 * 2.4+17 \quad 10$

PZE N9,0,64*1R+12 11

P>E CNLON, $0,64 * 24+111 ?$

PZE MINUS, $0,64 * 12+5 \quad 13$

PZE MINUS, 0.64*17+8 14

PZF LF, 0,64*24+6 15

PZE N7,0,64*12+8 16

PZE N?+1,0,64*]2+4 17

PZE PLUS, $0,64 * 12+5$

PZE A, $0,64 * 36+10 \quad 21$

PZE D+1,0,64*30+12 ?2

$P Z E \quad 0,0,64 * 24+8 \quad 23$

$P \geq F=0,0,64 * 6+7 \quad 24$

$P>E L, 0,64 * 30+7 \quad 25$

P?F $L, 0,64 * 24+6 \quad 26$

P>F $6,0,64 * 18+17 \quad 27$

PZF $\mathrm{H}, 0,64 * 36+6 \quad 30$

PZE RP, 0,64*12+6 31

$P Z E N 2+1,0,64 * 24+4$

PZE N7,0,64*12+5 33

PZE RP, $0,64 * 30+4$

PZE AR, 0,64*18+5 35

PZE MINIJS, 0,64*30+8 36

P>E AST, $0,64 * 24+3 \quad 37$

$P>F$ MIN!II, $0,64 * 30+2 \quad 40$

$P>E U, 0,64 * 17+5$

P7E M, 0,64*19+7 4?

P7E L, $0,64 * 30+3 \quad 43$

PZE $M, 0,64 * 36+5 \quad 44$

PZE N, 0,64*18+4 45

PZE $0,0,64 * 36+11 \quad 46$

PZE W, 0,64*18+7 47

PZE $0,0,64 * 7,4+11$

PZE W, 0,64*18+10 51

PZE PER, 0,64*36+14 5?

$P>E \quad N 7+1,0,64 * 6+11$

P>E AST, 0,64*1?+11

$P>F \mathrm{~N} I, 0,64 * 2,0+5 \quad 55$

P? $T, 0.64 * 12+5 \quad 56$ 


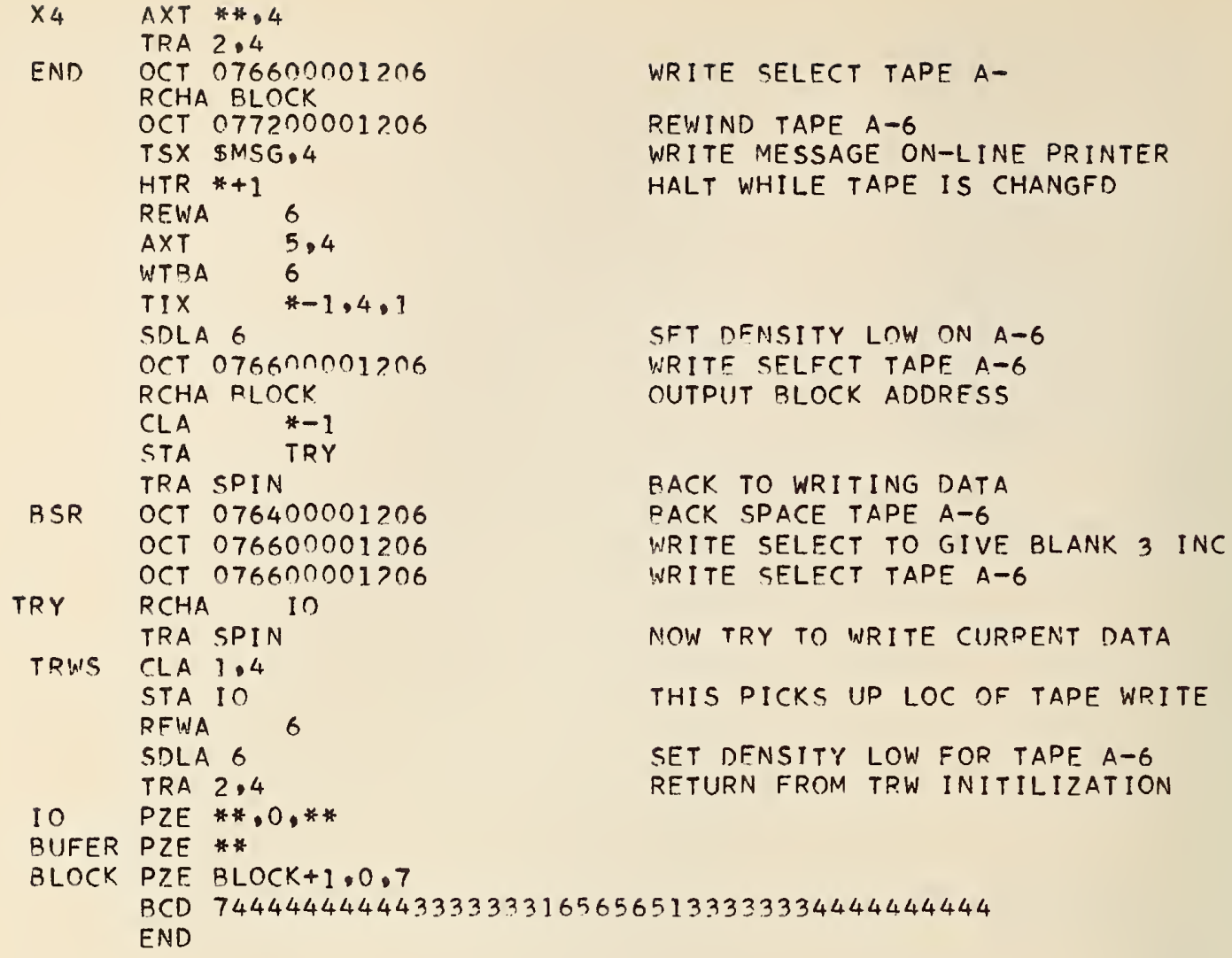





